\title{
DERECHOS DE PROPIEDAD INFORMALES Y GESTIÓN COMUNAL DE LAS PESQUERÍAS EN EL PAÍS VASCO. UN ENFOQUE ECOLÓGICO-INSTITUCIONAL
}

\author{
ERNESTO LÓPEZ LOSA \\ Departamento de Historia e Instituciones Económicas \\ Universidad del País Vasco/Euskal Herriko Unibersitatea
}

\section{RESUMEN}

Este trabajo tiene como objetivo estudiar el papel desempeñado por las cofradias de mareantes en el desarrollo y la gestión de la pesca en el País Vasco hasta principios del siglo xx. Gracias a un marco institucional particular, los gremios vascos construyeron un modelo de gestión específico que permitió la explotación exclusiva de los recursos pesqueros en la costa vasca. Una parte importante del carácter de este régimen de explotación se deriva de las particularidades de los recursos pesqueros y de los mercados de la pesca, pero también está relacionado con un modelo histórico de organización y de relación de la sociedad con la naturaleza. Finalmente, se presentan las consecuencias sociales y económicas de la transformación de la base legal que indirectamente sustentaba el aprovechamiento exclusivo en el último cuarto del siglo xix.

\section{ABSTRACT}

This paper deals with the role played by the Maritime Guilds in the development and management of the fisheries conducted from the Basque shore until the first half of the $20^{\text {th }}$ century. It contends that thanks to a particular institutional framework Guilds were able to build up a management model based on the exclusive use of the fishing resources. The character of this regime of use stems from the behaviour of the fishing resources and from the characteristics of the fish markets in Spain before the $20^{\text {th }}$ century, but it is also related to an historical model of organisation and relationship between

$N$. de E.: Fecha de recepción del artículo: febrero, 2002.

Fecha de aprobación por el Consejo de Redacción: enero, 2003. 
society and nature. Finally, the social and economic consequences of the process of institutional change that eliminated the legal basis of the exclusiveness are analysed.

JEL classification: N53, Q22.

\section{INTRODUCCIÓN}

Desde hace unos años están proliferando los estudios enfocados hacia el análisis de las complejas relaciones existentes entre las instituciones sociales y el funcionamiento de las economías, tanto presentes como pasadas. Los Premios Nobel concedidos a R. Coase en 1991, y a D. C. North dos años después, han dado un fuerte empujón a lo que se conoce como Nueva Economía Institucional (NEI), lo que en opinión de algunos no sería sino el reconocimiento de la insuficiencia de una teoría neoclásica que consideraba las instituciones como un elemento exógeno en el análisis de la realidad económica. Pero la NEI acaba pasando por ser algo más amplio que una simple nueva forma de análisis económico ${ }^{1}$. A pesar de la complejidad real existente para extraer un cuerpo teórico común ${ }^{2}$, la gran variedad de visiones y de posibilidades que ofrece hace que sea muy atractiva; sobre todo, por la importancia que se otorga a las instituciones y a la historia en la comprensión del funcionamiento de las economías y el desarrollo económico en general ${ }^{3}$. Algo parecido señala North cuando dice que la historia importa, y no sólo por lo que podamos aprender del pasado, sino porque el presente y el futuro están conectados con el pasado a través de la continuidad de las instituciones ${ }^{4}$. Es aquí donde el concepto de éstas como convenciones sociales alcanza relevancia. Únicamente si se comprende que las leyes sociales no son como las de la física, que tienen una lógica interna con muy poca relación con el contexto social, se entenderá la importancia y la historicidad de las instituciones, ya que el sistema legal evoluciona con el conjunto de la sociedad; en ocasiones, participando

1 Eggertsson (1995), p. 17. Una visión interesante de la NEI en Caballero (2001).

${ }^{2}$ Bo Gustafsson define a la NEI como un concepto o término paraguas bajo el que se reúnen una larga variedad de teorías o de fragmentos de teorías. Gustafsson (1998), p. 6; en este sentido ver también Toboso (1997), p. 177.

${ }^{3}$ Como ha escrito Alston, las instituciones son elementos históricos especificos, y por ese motivo hay que tener muy en cuenta su contexto histórico. Alston (1996), p. 25. Este autor remite incluso a argumentos similares utilizados por Stephen Jay Gould en el análisis de la evolución de las especies.

${ }^{4}$ North (1990), p. vii. 
conscientemente en el curso del cambio social y, en otras, simplemente, respondiendo pasivamente a las nuevas circunstancias 5 .

La importancia que la NEI otorga a la trayectoria histórica de las instituciones coloca a la historia económica en un primer plano. En cierto modo, se podría hablar de una Nueva Historia Económica Institucional (NHEI) que estaría logrando rendimientos crecientes en cuanto al estudio y la comprensión de la importancia de los derechos de propiedad, reglas o leyes de carácter público general, los costes de transacción o el propio cambio institucional. Sin embargo, mientras que el análisis de las instituciones como normas legales generadas por los Estados ha conocido un importante desarrollo desde que North y Thomas publicaran en 1973 su The Rise of the Western World algunos autores han señalado que seria interesante estudiar también otro tipo de instituciones que no tienen por qué ser de carácter exclusivamente legalista, y que influyen de manera directa en el desarrollo organizativo e institucional de las sociedades. En esta dirección apunta la propuesta de Greif de crear un nuevo instrumento al que denomina Análisis Histórico Institucional (Historical Institutional Analisis), que compartiría los presupuestos básicos de la NHEI, pero que haría especial incidencia en que, frente a los caminos o límites exógenos establecidos por el sistema legal, pueden existir también una multitud de limitaciones o de vías endógenas que ciertas prácticas o instituciones pueden imponer; es decir, no siempre los individuos van a seguir y respetar normas porque sean leyes. En un ámbito ajeno al sistema legal establecido, el comportamiento de los individuos puede ser conducido por normas de tipo consuetudinario, creencias u organizaciones que constituyen las reglas de juego ${ }^{6}$. Lo realmente llamativo de esta perspectiva de investigación es que el análisis empírico microinstitucional acaba mostrando en muchos casos la emergencia, espontánea o impulsada conscientemente, de comportamientos económicos homogéneos entre aquellos que forman parte de esa organización o comunidad ${ }^{7}$. Sería interesante, entonces, analizar los motivos que hacen que los individuos cumplan y acepten las reglas de juego establecidas, y, por lo tanto, también admitan la capacidad de coerción de la que dispone la comunidad para asegurarse una homogeneidad productiva sin tener que recurrir al aparato estatal. Todo esto engarzaría con una amplia literatura socioantropológica, pero también económica, vinculada

'McEvoy (1993), p. 13.

6. Greif (1997a), pp. 82-83; Greif (2000), pp. 256-257; ver también Engerman (1997).

7 Algunas propuestas en Greif (1997b). 
al estudio de formas de aprovechamiento de recursos naturales en distintos momentos históricos ${ }^{8}$. La evaluación de la eficiencia económica de las instituciones, que se presenta como un aspecto relevante en el análisis económico institucionalista, ha de complementarse entonces también con un análisis de su eficiencia social en un marco de relaciones sociales de producción que no es ahistórico, sino que pertenece a un mundo y a un tiempo determinado.

El objetivo de este texto es analizar el funcionamiento de las cofradías de mareantes en el País Vasco y la manera en la que han intervenido históricamente en la actividad pesquera. En las páginas siguientes se tratará de explicar cómo, gracias a un marco institucional particular, los gremios marítimos vascos construyeron un modelo de gestión específico que tendría como elemento clave la asignación indirecta de unos derechos de propiedad que permitieron durante varios siglos la explotación exclusiva de los recursos pesqueros en la costa vasca. Sin embargo, esa realidad se correspondía con un entorno institucional determinado que, sin ser estático, se hallaba claramente condicionado por una realidad socioeconómica y tecnológica no excesivamente dinámica. Enfrentadas a una incertidumbre constante que tendría su origen en las limitaciones técnicas existentes para enfrentarse a un medio extraño, como es el océano, y a unos recursos muy variables, las comunidades pesqueras vascas desarrollaron mecanismos de adaptación y defensa tanto frente al medio natural como también frente a su entorno social. En este contexto, el conocimiento, resultado de la experiencia acumulada en su devenir histórico, desempeña un papel determinante en la caracterización del funcionamiento socioeconómico de los individuos o de las comunidades 9 .

\footnotetext{
${ }^{8}$ Algunas vinculaciones sugeridas entre la antropología marítima y la economía institucional en Breton; Savard (1999).

${ }^{9}$ Como ha escrito McEvoy, «El conocimiento se manifiesta en los individuos como la comprensión de sí mismos y de su posición social en el mundo. El conocimiento existe también al nivel social, donde aparece en forma de cultura, ideología y derecho; ellos hacen que las comunidades perciban el mundo y se comporten hacia él de modo particular. Todo lo que las personas hacen tiene algún impacto eni la Naturaleza, lo que a su vez provoca que las economías y las culturas se enfrenten con nuevas situaciones ecológicas a las que deben adaptarse o bien desaparecer». McEvoy (1993), pp. 190-1991. Ver también McEvoy $(1989,1990)$.
} 


\section{EL ORIGEN Y LAS CARACTERÍSTICAS BÁSICAS DE LAS COFRADÍAS DE MAREANTES}

La carencia casi absoluta de fuentes hace difícil acercarse con un mínimo de fiabilidad al origen de las cofradías de mareantes, y ello posiblemente haya facilitado la aparición de numerosas interpretaciones legendarias y acríticas. En cualquier caso, las tesis más fundadas situarían el origen de los gremios de mareantes en el País Vasco, y probablemente también en el resto de la costa cantábrica, en un contexto de expansión del gremialismo en la Europa occidental durante la Baja Edad Media y que, con una influencia especialmente francesa, llegaría a través del Camino de Santiago ${ }^{10}$. Existiría otra teoría interesante que ligaría el desarrollo de la pesca en el Cantábrico, y posiblemente la aparición de gremios, con el acceso a propiedades en la costa de grandes monasterios, como el de San Millán, en el caso vizcaíno, o del de Cluny en el de Laredo ${ }^{11}$, lo que podría llevar sus orígenes hasta los siglos XI o XII; sin embargo, a pesar de la estrecha vinculación que las cofradías han tenido históricamente con la Iglesia, y el evidente interés en el desarrollo de la pesca por parte de las órdenes monásticas ${ }^{12}$, no hay evidencia documental que ligue su origen con la presencia de las citadas órdenes. Si bien es cierto que no se podría negar la posible existencia en períodos anteriores de alguna manifestación de tipo protogremial, las primeras referencias documentadas en el País Vasco se remontan únicamente hasta la primera mitad del siglo XTV ${ }^{13}$.

Las cofradías de mareantes cumplían con las premisas típicas de los gremios profesionales. Aunque también hayan sido definidas como asociaciones piadoso-profesionales, o se haya hecho más hincapié en su carácter benéfico o asistencial, sobre todas las cosas, eran asociaciones de tipo profesional. Su función principal era la regulación de la actividad pesquera, tanto a través del control de la mano de obra, de los tiempos o técnicas empleadas en la pesca como de la comercialización del producto mediante la venta centralizada. Compartiendo otra característica común a muchos gremios, también eran excluyentes. Cada cofradía únicamente aceptaba en su seno a mareantes y pescadores que fueran vecinos del puerto, e

${ }^{10}$ Erkoreka (1991), pp. 31-34, 45; Tena García 11995), p. 144; García de Cortázar (1966), p. 117.

"1 Moreda Oroza (1966) citado en Bikandi (1989), p. 19.

12 Para el caso vizcaíno, García de Cortázar (1969).

13 Sobre la datación de las cofradías vascas, Erkoreka (1991), pp. 44-77. 
impedía la participación, tanto en la pesca como en la comercialización de todos aquellos individuos ajenos a la misma ${ }^{14}$.

La formación y el funcionamiento histórico de las cofradías de mareantes también se pueden analizar desde otra perspectiva. En un medio hostil y peligroso para el hombre como es el mar, y frente a unos recursos difícilmente controlables y apropiables, la actividad pesquera viene caracterizada por un alto grado de incertidumbre y de riesgo. Una de las principales características de los recursos pesqueros es su variabilidad en el espacio y en el tiempo. Esto ha dado pie a que se hable de unos imperativos ecológicos que hacen que su disponibilidad fluctúe temporal y espacialmente en ciclos de corta o larga duración, proceso en el que interviene de manera directa el propio comportamiento biológico de las especies, pero que también puede venir causado por factores oceanográficos o climatológicos ${ }^{15}$. $\mathrm{La}$ acumulación de conocimiento sobre estas situaciones y su transmisión durante generaciones ha hecho que el pescador haya podido adaptarse en la medida de lo posible a esa incertidumbre productiva. Pero también las instituciones de gobierno que crean los pescadores se pueden entender como mecanismos de defensa. En este caso se trataría no sólo de protegerse de la incertidumbre causada por la particularidad del medio natural, sino también de la derivada del entorno social que les rodeaba.

En este sentido, los gremios marítimos funcionarían como instituciones cuyo fin principal sería reducir o intentar atenuar los riesgos vinculados a la actividad pesquera. Primero, a través de medidas tendentes a mitigar los peligros de la propia pesca en el mar; segundo, en un mundo de demanda limitada e irregular, estableciendo las mejores condiciones posibles para conseguir un mínimo de rentabilidad en la venta del pescado. En la vida

${ }^{14}$ Un claro ejemplo es el proyecto de nuevas ordenanzas de la Cofradía de Bermeo de 1878, donde aparecían artículos como los siguientes: Art. 70: «El vecino de esta villa que sea dueño de embarcación no inscripta formalmente en esta cofradía no podrá egercitarla á la pesca desde este Puerto pena de caer en decomiso la que hiciere, cuyo importe en pública subasta ingresará en los fondos comunes de la misma Cofradía.» Art. 71: «No podrá tripular embarcación inscripta ninguna persona no inscripta en esta cofradía, pena de diez pesetas [...].» Art. 72: «No se admitirá á inscripción á esta Cofradía embarcación pescadora traida de fucra en alquiler, ni la tripulará nadie para egercitarse á la pesca desde este Puerto, [...].» Art. 99: «Toda embarcación que desde este Puerto se egercite á la pesca en cualquiera época del año, quedará por el mismo hecho obligada sin escusa ni pretesto al cumplimiento exacto y puntual de estas Ordenanzas y en especial al de las señales que haga la señera ó contra-señera en sus casos [...].» Archivo Museo Don Álvaro de Bazán (AMDAB), Pesca, Asuntos Particulares, legajo 2147.

${ }^{15}$ El concepto de imperativo ecológico en Maiz (1993), pp. 109-110. 
de los núcleos costeros preindustriales la incertidumbre y la inseguridad estaban presentes de manera continua; períodos de malas capturas, de descenso en los niveles de comercialización por causas relacionadas con cambios o dificultades en unos mercados ya de por sí limitados, junto con el peligro latente de la pérdida de vidas o medios de producción en la mar, por citar algunos, eran problemas que influían en las condiciones económicas y sociales de las comunidades de pescadores. La posibilidad de acceder a mercados de crédito o seguros podría haber atenuado los problemas resultantes. Sin embargo, en su ausencia, el gremio era el encargado de velar tanto por la seguridad como por la subsistencia de sus miembros y sus familias, centralizando las peticiones de crédito y, de la misma manera, las subvenciones por las pérdidas, los repartos de grano en tiempos de malas capturas, $u$ ofertando asistencia médica y monetaria tanto a los pescadores retirados como a las viudas y huérfanos sin posibilidad de ingresos. Al fin y al cabo, y parafraseando a Eggertsson, las cofradías de mareantes podrían ser identificadas como instituciones de gestión del riesgo (Institutions of Risk Management) ${ }^{16}$.

\section{LAS COFRADÍAS Y LA GESTIÓN COMUNAL EN LAS PESQUERÍAS VASCAS}

Una de las claves en el funcionamiento de los gremios pesqueros vascos hasta fines del siglo XIX fue el establecimiento de un régimen de aprovechamiento exclusivo de los recursos pesqueros. Esta situación nos induce a examinar varios aspectos vinculados al mismo: primero, el ejercicio de unos derechos de propiedad y su fuente de legitimidad; segundo, sus características y objetivos - es decir, la manera en la que los gremios pudieron ejercerlos, para qué y para quién-; tercero, las relaciones de las cofradías de mareantes con fuentes de legitimidad superior, como el Estado, o su reacción ante la aparición de individuos o instituciones interesados en participar en las pesquerías.

La definición de los derechos de propiedad es uno de los elementos centrales dentro de la NEI. Ahora bien, durante mucho tiempo se ha tomado como punto de partida en su análisis la asunción de que todas las actividades económicas tienen lugar dentro del contexto institucional de un Estado liberal ${ }^{17}$. Sin embargo, algunas de sus primeras aplicaciones

\footnotetext{
${ }^{16}$ Eggertsson (1998).

17 Furubotn y Richter (1997), p. 71.
} 
teóricas fracasan al aplicar los mismos conceptos en comunidades que tenían otros fundamentos sociales y culturales ${ }^{18}$. Comentarios similares se podrían hacer a North y Thomas cuando señalaron que el surgimiento de derechos de propiedad de carácter individual fue el elemento que permitió a las comunidades comenzar a generar incentivos para mejorar la productividad y la eficiencia, frente al carácter desincentivador de los derechos de propiedad comunes sobre los recursos ${ }^{19}$. Es evidente que el aliciente del aprovechamiento exclusivo ha sido un elemento crucial en el desarrollo económico; sin embargo, éste no tiene por qué ser relacionado única y exclusivamente con la propiedad individual. Durante mucho tiempo el aprovechamiento comunal de algunos recursos ha supuesto la pervivencia de muchas comunidades a lo largo y ancho del planeta, y ello difícilmente cuadraría con la supuesta asignación ineficiente de recursos que habitualmente se ha achacado al mismo. Todo ello tiene mucho que ver con el concepto que se tenga de propiedad y, más en concreto, de propiedad o gestión comunal.

Los derechos de propiedad deben analizarse necesariamente desde la perspectiva del entorno institucional en el que están insertos, en el que los acuerdos que se encuentran en su origen se definirían como las reglas y convenciones que establecen la relación de los individuos con los recursos económicos, que transforman el interés en demanda, y las demandas en derechos de propiedad ${ }^{20}$. Ese entorno institucional, las creencias o las convenciones sociales que lo sustentan, también puede ser resultado de limitaciones tecnológicas, económicas, o de otras generadas por el propio medio natural. Frente a la supremacía de los derechos de propiedad individuales, y a la idea generalmente aceptada e inicialmente difundida a través de los clásicos trabajos de Gordon y Hardin ${ }^{21}$, de que la propiedad comunal provocaba invariablemente una disipación de renta y una explotación incontrolada de los recursos (la famosa Tragedy of the Commons), hace tiempo que una amplia y variada literatura ha demostrado que el uso comunal de recursos naturales no era sinónimo de libre acceso, sino que éste comportaba ciertas características particulares que diferenciaban claramente la Res Comunes de la Res Nullius 22 .

${ }^{18}$ Ver, por ejemplo, Demsetz (1967). También Eggertsson (1995), pp. 244-246.

19 North y Thomas (1977), p. 229.

${ }^{20}$ Gibbs y Bromley (1989), p. 22.

${ }^{21}$ Gordon (1954) y Hardin (1963).

22 Bromley (1991, 1992); Berkes y Farvar (1989); Ostrom (1990): Fenny, Berkes, McCay y Acheson (1990); Eggertsson (1992, 1995); Aguilera Klink (1991); Ciriacy-Wintrup y Bishop 
Sobre esta serie de conceptos se establecen unos mínimos característicos de lo que se podría definir como gestión comunal. El primero sería la existencia de límites que determinan quién tiene acceso al recurso y quién no; es decir, el concepto de exclusión, sin el que la propiedad y la gestión comunal no podrian entenderse. Por otra parte, y aunque en el espacio y en el tiempo sus características varían con relación a las situaciones particulares y a los objetivos que se persiguen, otro elemento común sería la existencia de reglas e instituciones, generalmente fundamentadas en la costumbre, a través de las que se establecen las formas en las que debe llevarse a cabo el aprovechamiento. Estas normas, que se pactan entre los miembros de la comunidad, y que pueden cambiarse de común acuerdo según surjan nuevas circunstancias o problemas, también incluían habitualmente medidas de carácter coercitivo para asegurar su cumplimiento ${ }^{23}$. En general, son las reglas que se establecen entre los componentes del grupo las que acaban, o pueden acabar dando origen a la aparición y desarrollo de derechos que, por su parte, no pretenden sino buscar un comportamiento productivo homogéneo entre todos ellos, y que no necesariamente tienen que tener reconocimiento directo de autoridades superiores ${ }^{24}$.

Pero el régimen de propiedad no llega a aclarar completamente la cuestión de los derechos de propiedad, puesto que recursos comunes pueden ser explotados bajo múltiples formas de aprovechamiento, no necesariamente comunales. Por este motivo, algunos autores distinguen entre el régimen de propiedad y las formas de gestión. En algunos casos, como en el de los denominados recursos de aprovechamiento común (Common Pool Resources) las circunstancias se complican. Desde el punto de vista de los recursos pesqueros, por ejemplo, existen grandes problemas para definir límites o restringir el acceso a potenciales usuarios; las peculiaridades del medio marino hacen que el establecimiento de derechos exclusivos sea difícil. Derivado de ello, otra de sus características sería la sustracción: cualquier persona puede tener la capacidad de extraer riqueza de los mismos y, de la misma manera, la de poder afectar al rendimiento futuro de otros optantes ${ }^{25}$. De ahí que distinguir entre el recurso y el régimen

(1992); González de Molina y González Alcantud (1992); Iriarte (1998); Moreno Fernández (1998).

${ }^{23}$ Un funcionamiento asegurado, al fin y al cabo, a través de lo que McEvoy define como mutual coertion mutually agreed upon. McEvoy (1988), p. 227.

${ }^{24}$ Ostrom (1990), pp. 88-102; Schlager y Ostrom (1992), pp. 249-254.

${ }^{25}$ Feeny, Hanna y McEvoy (1996), p. 187; Feeny, Berkes, McCay y Acheson (1990), pp. 3-4; Schlager, Blomquist y Tang (1994), p. 295. 
de propiedad sea tan importante. En cierto modo, la distinción que realiza Elinor Ostrom entre Sistemas de Recursos (Resource Systems) y Unidades de Recursos (Resource Units) producidas por los sistemas aporta mayor claridad a la hora de diferenciar entre los recursos en sí y sus formas de aprovechamiento $^{26}$. Por una parte, estaría el recurso, y, por otra, las unidades que los usuarios extraen del mismo. Es muy importante advertir que la propiedad no se establece sobre el recurso en sí, sino sobre las unidades que se obtienen del mismo. Lo interesante, entonces, es saber cuáles son las normas que regulan este aprovechamiento, sus razones y los objetivos que se persiguen.

\subsection{Bases institucionales y propiedad informal}

En el caso que nos ocupa, la propiedad o gestión comunal ejercida por las cofradías de mareantes habría que entenderla como un sistema de autoridad que se inserta en una estructura social superior concreta que le da sentido y le garantiza, directa o indirectamente, su existencia. Por lo tanto, sus características están enraizadas en las prácticas habituales de esa fuente de autoridad superior, y de la supervivencia de ésta depende también la de los sistemas de propiedad establecidos sobre ella ${ }^{27}$.

En principio, los recursos pesqueros entrarían dentro del grupo de bienes que serían de uso libre. Así lo aseguraban las Partidas al afirmar que «las bestias salvajes e las aves e los pescados del mar, quien quier que los prenda, son suyos» ${ }^{28}$. Sin embargo, este precepto y otros similares tenían una excepción, y era que esto era posible mientras no ocurriera en heredad ajena sin permiso del señor. El mar era heredad real, y, por lo tanto, lo eran también las rentas que sus recursos generaran, como se afirma en la Ley XI, Título XVIII, Partida Tercera:

«[...] e las rentas de las salinas o de as pesqueras son de los Emperadores e de los Reyes e fuéronles otorgadas todas estas cosas porque oviesen con que se mantuviesen honradamente en sus despensas e con que pudiesen

${ }^{26}$ Ostrom (1990), p. 31.

${ }_{27}$ Bromley (1991), p. 92; (1992), pp. 9-10.

${ }^{28}$ Ley XVII, Título XXVIII, Partida Tercera recogido en Ciriquiaín Gaiztarro (1961), p. 39. La Ley III, Título XXVIII, Partida Tercera, señala «cosas que (pertenecen) comunalmente a todas las criaturas que viven en este mundo son estas: el ayre, e las aguas de la lluvia, e el mar e su ribera. Ca cualquier criatura que bive, puede usar de cada una de estas cosas según quel fuere menester». Citado en Nieto (1968), p. 4. 
amparar sus terrenos e sus reinados e guerrear contra los enemigos de la Fe» ${ }^{29}$.

Por razones evidentes, esa propiedad se plasmaba en la práctica en una serie de prestaciones o derechos que los pescadores satisfacían al monarca o a sus delegados. Ciertamente, este concepto de propiedad no tiene su origen en las Partidas, ya que la monarquía había venido ejerciendo derechos similares, directa o indirectamente, desde tiempo atrás ${ }^{30}$; los testimonios que se pueden encontrar sobre la concesión de privilegios de pesca en pago a servicios de tipo militar prestados por pescadores son relativamente abundantes ${ }^{31}$. Es más, en función de las necesidades de hombres para la Armada, que se incrementan notablemente a partir del siglo Xv, la monarquía esgrimiría, a través de una Real Cédula en 1544, la obligatoriedad de la prestación de servicios a cambio del derecho de pesca y navegación en sus dominios ${ }^{32}$.

En el País Vasco, debido a su situación administrativa particular, la recluta de marineros para la Armada acabó derivando con el tiempo en un sistema diferente al del resto de la Península. Aunque sus presupuestos básicos ya se habrían fijado en la segunda mitad del siglo xv, éste acabó desarrollándose en las Ordenanzas Generales de la Armada de 1748, completándose con una Real Orden de 17 de abril de 1752 expedida para el gobierno particular de la marinería de las provincias vascongadas y, ya definitivamente, en la Ordenanza General de Matrículas del 12 de agosto de 1802. A partir de las mismas se estableció que mientras realizaran su actividad dentro de sus aguas, los pescadores vascos no estaban obligados a matricularse, y dependían de la jurisdicción ordinaria ${ }^{33}$.

A pesar de que los Fueros supuestamente establecían la libertad de pesca y navegación para los habitantes de las provincias vascas costeras

${ }^{29}$ Ciriquiaín Gaiztarro (1961), pp. 39-40.

${ }^{30} \mathrm{Ya}$ en las cartas fundacionales de puertos como Bermeo o Lequeitio se recoge la obligatoriedad de pagar al Señor de Vizcaya el «quincio» del pescado capturado por sus habitantes. Ibidem.

${ }^{31}$ Fernández Duro (1881), p. 278; Salas (1879), p. 88; Zabala (1931), p. 289.

32 Zabala Uriarte (1981), p. 205; Zabala (1931), pp. $358-359$ (t. II).

${ }^{33}$ «La gente de mar de estas Provincias podrá pescar y navegar libremente en sus costas y embarcaciones que se habilitasen en sus puertos; pero no fuera de aquellas y dentro de los límites de las demás provincias, en que no disfrutarán del fuero y privilegios de Marina sin haber hecho una campaña, y estar formalmente alistados en sus respectivas cofradías de mar [...] en inteligencia de que en la pesca, navegación y qualquiera otra industria de mar en que se exerciten fuera de las Provincias Vascongadas, han de estar sujetos como los demas matriculados á la Jurisdicción de Marina.» Novisima Recopilación..., Libro VI, Título VII, Ley XII, art. $2^{\circ}$, p. 120. 
dentro de sus aguas, el modelo de reclutamiento para la Armada que se instituyó a partir de las leyes citadas acabó facilitando el monopolio gremial. Mientras que en la península la matrícula de marineros era una lista nominal, en el País Vasco, al no existir ésta, la Marina solicitaba un cupo de hombres partiendo de unas listas sobre el número de hombres hábiles e inhábiles existentes en cada puerto que las diputaciones remitían anualmente ${ }^{34}$. En función del número total de mareantes hábiles, se establecía una cantidad que luego las autoridades forales repartían entre las diferentes cofradías. A partir de ese momento, la cofradía se convertía en el centro del sistema. Al no existir la Matrícula, el gremio era quien se encargaba finalmente de cumplimentar las peticiones de marineros y, en consecuencia, todo aquel que quisiera pescar o navegar desde puertos vascos tenía que pertenecer a alguna cofradía. Ante una protesta elevada por unos miembros del gremio de Bermeo en 1861 que trataban de vender sus capturas fuera de la subasta en común, la comandancia de marina, a instancias de la cofradía, determinó lo siguiente:

«[... considerando que los cofrades o agremiados, al inscribirse en la cofradía, lo hicieron en el conocimiento de que la venta de la pesca era en común y que si han de gozar de los beneficios de la pesca y nabegación peculiares de la gente de mar, que es sólo la inscrita en la cofradía, están obligados a observar sus ordenanzas mientras se hallen vigentes, y á responder de las cargas, no sólo hasta el día, sino también a las sucesivas en la forma que establecen las Ordenanzas del Gremio, sin que puedan evadirse de su cumplimiento sino por la separación. Considerando que esta separación no puede ser parcial sino absoluta ó total, esto es, de beneficios y cargas. Además quien no lo respetare no puede ser cofrade, ni gente de mar sin poder navegar ni pescar» ${ }^{35}$.

Sobre estas bases institucionales se construyó lo que denominábamos como un régimen de gestión o de propiedad comunal. Y lo cierto es que aunque ninguna normativa jurídica lo sustentaba, la mezcla entre foralidad y el sistema particular de reclutamiento de marineros otorgó a las cofradías la exclusividad de la explotación de los recursos pesqueros en la costa vasca.

Sobre las Ordenanzas Generales de la Armada y su incidencia en Guipúzcoa, Egaña (1992), p. 342.

${ }^{34}$ Novísima Recopilación..., Libro VI, Título VII, Ley XII, art. 6., p. 120.

${ }^{35}$ Archivo Municipal de Bermeo (AMB), Caja 14, carta de la Comandancia de Marina de la Provincia de Bilbao al Alcalde de Bermeo, 19 de diciembre de 1861. 


\section{DERECHOS INFORMALES Y GESTIÓN BASADA EN LA COMUNIDAD}

¿Cómo definiríamos a la comunidad? ¿Cuáles serían los elementos que nos harian hablar de la existencia de una comunidad, y de ese comportamiento productivo particular que se ha citado antes como un componente importante en estos regímenes comunales? ¿Cómo y por qué los pescadores acaban reuniéndose en cofradías y funcionando durante siglos con las mismas? Evidentemente todas estas cuestiones necesitarían un análisis más extenso y profundo, pero unos pequeños apuntes quizá permitan comprender no sólo el porqué de su existencia, sino también sus actitudes en los momentos en los que su modelo de funcionamiento se veía amenazado.

Entre las muchas opciones que se podrían encontrar a la hora de identificar el contenido del concepto de comunidad, destacaría aquella que señala que el comportamiento de sus miembros estaría caracterizado por actitudes y objetivos comunes que surgirian de experiencias compartidas y de creencias sociales también comunes ${ }^{36}$. Los comportamientos homogéneos que aparecían entre los elementos característicos de la gestión comunal se entenderían entonces no sólo como producto del interés económico individual de agruparse en una institución, sino que también participarían en el mismo, y de manera intensa, elementos culturales y sociales que darían sentido a esas comunidades frente a otras ${ }^{37}$. La cofradía, por lo tanto, sería resultado de estos intereses comunes y cumpliría unas funciones concretas, como, por ejemplo, la reducción de la incertidumbre y del riesgo, la regulación y minimización de los conflictos, o la difusión de la información entre sus miembros a través de mecanismos como las juntas gremiales que se celebraban con regularidad y en las que se discutían tanto aspectos profesionales como de carácter social. Aunque no se traten en este trabajo, también los gremios de pescadores desempeñaban muchos otros cometidos al margen de los que vamos a tratar de explicar. Entre ellos destacan las que podríamos denominar funciones de tipo social, y que son asimismo importantes para entender estas instituciones. Las cofradías no sólo se dedicaban a organizar todo aquello relacionado con la profesión, sino que también cuidaban de la-situación de sus agremiados y

${ }^{36}$ Sobre estas cuestiones, Swaney (1990).

37 Por ejemplo, en Bermeo los pescadores siempre han tratado de distinguirse del resto de la población, siendo ellos los arrantzaliek (pescadores) y el resto de la población, en mayor o menor grado, los terrestriek (terrestres). 
sus familias, ofreciéndoles diversos servicios y sustento económico en los momentos en los que la pesca era escasa. Para estos fines, todos los cofrades contribuían con una serie de porcentajes de lo obtenido en la venta del pescado, o en el caso de los marinos, con mareajes o con cantidades fijas de dinero ${ }^{38}$.

De algunas de las características apuntadas más atrás, cabría la posibilidad de que se llegara a identificar a esta gestión comunal como igualitaria. Quizá nada más lejos de la realidad. Aunque en sus orígenes la impresión que ofrecen las fuentes es que todos los cofrades participaban en igualdad de condiciones, es probable que, en la realidad, el gremio fuera controlado por los maestres y propietarios de lancha. Sin embargo, la parquedad de las mismas no permite mayores precisiones. En cambio, desde el siglo xvI está documentado un proceso de diferenciación entre sus componentes, cuyo resultado fue el control progresivo de los órganos de decisión por parte de los dueños y patrones de las embarcaciones, que fue prácticamente total ya durante el XvIII y el XIX ${ }^{39}$.

\subsection{La organización del proceso productivo y de la venta}

La normativa gremial, basada en la costumbre y, por ende, no escrita explícitamente en muchas de las ocasiones, abarcaba prácticamente todos los aspectos concernientes a la actividad extractiva: el tiempo de pesca en el mar, cuándo se había de salir a pescar y cuándo regresar al puerto, qué tipo de embarcaciones se podían utilizar o cuáles eran las características que cada lancha debía tener para poder dedicarse a una pesca o a otra, la duración de las costeras, las artes o aparejos a emplear, cuál era la relación entre los pescadores y los patrones y la de éstos con respecto a la agremiación, etcétera. En consecuencia, el desarrollo de la actividad productiva no dependía de las decisiones individuales de cada pescador, sino que era resultado de las tomadas en conjunto por los miembros de la cofradía. Además, los gremios establecían medidas de tipo coercitivo (multas, incautación de las capturas, prohibición de salir a la pesca) a través de las cuales se pretendía forzar su cumplimiento. Los objetivos que se perseguían con la regulación precisa de todos estos aspectos eran múltiples, pero, sobre todo, vamos a tratar aquellos relacionados con la seguridad en las faenas

${ }^{38}$ Erkoreka (1991), pp. 319-329.

39 Erkoreka lo define como de oligarquización (1991), p. 135. Sobre la evolución de este proceso durante el xvil y el xvu, ibidem, pp. 124-136. 
pesqueras y su reglamentación, y con la venta de la pesca. En un pleito celebrado en los años sesenta del siglo XXX, el gremio bermeano resaltó lo siguiente:

«Estas ordenanzas son la base de la cofradia de pescadores de Bermeo y sobre ellas a funcionado tomando acuerdos y disposiciones para el bien de los cofrades, procurando la conservacion de sus privilegios, usos y costumbres. Unas de las bases mas cardinales de esta cofradia son la venta en comun del pescado, satisfaciéndolos derechos que se estipulan para atender á sus necesidades y la obligacion de guardar la hora para la salida de la pesca y la obediencia á la señal que hagan los alcaldes de mar ó señeros en alta mar cuando por aparato de mal tiempo crean que se deba arribar al puerto» ${ }^{40}$.

a) La salida a las calas y la vuelta a puerto: de la seguridad al interés económico

Una de las cuestiones en las que las cofradias hacían más hincapié era la seguridad en las faenas pesqueras. La fragilidad de las embarcaciones utilizadas hasta tiempos relativamente recientes, por lo menos hasta la aparición de la propulsión mecánica, así como las propias características del medio, o las barras de arena que dificultaban la entrada de la mayor parte de los puertos generaban con frecuencia naufragios o accidentes más o menos graves. En este sentido, los gremios establecieron lo que podríamos denominar como pesca en conjunto: es decir, la salida y la vuelta al puerto debían realizarla todas las embarcaciones a la vez. Para regular y controlar este proceso, las cofradías disponían de cargos específicos, entre los que destacaban los llamados señeros, que eran quienes decidían si se podía salir a la mar o cuándo había que volver y por qué al puerto, además de vigilar la entrada en el mismo. La misma cofradía de Bermeo en el documento citado en la nota anterior señala que

«respecto á la razón que tuvieron los antiguos al establecer la obediencia á los señeros o alcaldes de mar, la esperiencia por desgracia ha justificado su necesidad. Nadie de buena fe puede desconocer que la industria de la pesca es muy comprometida y está espuesta á infinitos peligros que llevan el terror y el espanto á las poblaciones cuyos individuos han tenido la desgraciada suerte de perecer en un naufragio y que esta industria debe estar regularizada sopena de esponer á los habitantes de los puertos pescadores á continuos riesgos é irreparables pérdidas materiales y personales que por desgracia son sobrados frecuentes. Para atenuar estos males, es para lo que

${ }^{40}$ Archivo General del Señorio de Vizcaya (AGSV), Pesca, Registro 3, legajo 1, núm. 13. 
se nombran los señeros de mar que entendiéndose con el talayero á que se situa en la cima del Cabo Machichaco, observan el tiempo y cuando por sus cálculos creen que corre peligro, hacen la señal de arribar a puerto á fin de salvarse» ${ }^{41}$.

No obstante, además de la seguridad, y como en esta cita se puede apreciar, detrás también había argumentos de carácter económico. Por una parte, estaban los desembolsos que suponían para las cofradías los pagos por las embarcaciones o las artes perdidas, o las cantidades que se entregaban a las viudas y huérfanos de los pescadores desaparecidos. Pero, por otra parte, también la salida y el regreso en conjunto permitían controlar de manera más eficiente la venta de las capturas y la recaudación de los porcentajes con los que los pescadores contribuían para el mantenimiento del gremio y sus funciones. Como indica la Cofradía de Elanchove a cuenta de un pleito que interpuso un patrón contra la misma en el primer tercio del siglo XIX.

«[...] que el gremio de mareantes es una sociedad cuyos individuos están constituidos á sobstenerla proprocionando las ganancias del arriesgado oficio de la pesca. Si se distraen los pescadores a otros destinos con sus lanchas: si se separan, y hiuen a otros puertos, ni puede responder á las obligaciones, que tiene contra si el Gremio» ${ }^{42}$.

\section{b) La venta del producto}

Como aparecía en alguna de las citas anteriores, el control de la comercialización, constituía una «de las bases más cardinales» del funcionamiento gremial. Era, al fin y al cabo, el principal instrumento con el que defender la exclusividad. Desde el momento en el que las limitaciones técnicas hacían imposible impedir el acceso de otros optantes a las áreas de pesca, ésta sólo podía ser ejercida si la cofradía controlaba de manera monopolística la comercialización del pescado ${ }^{43}$. La venta era, por lo tanto, el elemento clave del monopolio gremial. En principio, nadie que no fuera miembro de la cofradía podía pescar, ni, por lo tanto, vender. Pero la pertenencia a la misma no aseguraba tampoco libre disponibilidad de las capturas,

${ }^{41}$ AGSV, Pesca, Registro 3, legajo 1, núm. 13.

${ }^{42}$ Archivo Foral de Bizkaia (AFB), Corregimiento de Busturia, 259/1.

${ }^{43}$ Salvando las distancias, las prácticas de las cofradías vascas vienen a coincidir, a grandes rasgos, con las recomendaciones de los técnicos actuales para la gestión eficiente de los recursos pesqueros. Ver, por ejemplo, Hannesson (1993), pp. 112-113. 
sino que la venta de todas aquellas especies que el gremio consideraba importantes por ser las más demandadas (besugo, merluza, bonito, atún, congrio, etc.), debía centralizarse y su subasta era controlada por los cargos del mismo. Por otra parte, los pescadores también solían tener problemas cuando pretendían vender la pesca en algún puerto diferente al suyo, siempre que no fuera por causa de arribadas forzosas. En realidad, sólo tenían capacidad de vender por libre aquellas especies carentes de especial interés para los compradores, como ocurría con la anchoa y, en algunos puertos, con la sardina hasta finales del siglo $\mathrm{Xx}^{44}$.

En principio, aunque tampoco las fuentes son muy explícitas al respecto, parece que hasta el siglo XVI aproximadamente, los gremios no controlaban la comercialización de la pesca. Sin embargo, a partir de entonces, la expansión de la venta en común de las capturas de todos los cofrades fue imponiéndose, primero en las cofradías más grandes, hasta llegar a las más pequeñas para el siglo XviII o principios del $\mathrm{XIX}^{45}$.

¿Por qué se llegó a centralizar la venta del pescado? Uno de los principales objetivos que se perseguía era la obtención de un precio de venta aceptable para el conjunto de los pescadores, algo que se intentaba conseguir también complementando la subasta diaria del pescado fresco con los llamados remates por adelantado de parte de las capturas. Concentrando la oferta se tenían más posibilidades de negociar precios que si cada pescador vendía sus propias capturas por libre. Además, hay que tener en cuenta que la centralización conllevaba lugares de venta, fechas, horarios más o menos establecidos, lo que también servía de incentivo para la formación de una demanda relativamente estable. Por otra parte, esto significaba para las comunidades de pescadores poder intercambiar con cierta regularidad sus productos por otros de necesidad. Es evidente que el pescado les servía de alimento pero también lo es que era una mercancía gracias a cuyo intercambio obtenían otra serie de productos básicos. Por ejemplo, las Ordenanzas de un puerto pequeño como el de Rentería de finales del siglo Xvin decían:

«La Arriería que vaja de Navarra a Aragón conducirá de necesidad á su venta vinos, Lino, Jabón, garvanzo y otros comestibles á precios equitativos en conocido alivio de estos havitantes. Las mugeres aun tendran continuo empleo y ganancias en la conducción, limpia y venta del pescado y ulti-

44 Un desarrollo más amplio en López Losa (2000), pp. 131-164.

45 Erkoreka (1991), pp. 277-278. 
mamente por todo lo expuesto y otras ventajas que no se dudan será evidentemente trascendental á todos el fruto de este establecimiento» ${ }^{46}$.

Junto con la venta en común, el segundo pilar sobre el que se sostenía el sistema de comercialización exclusiva era el remate antes del inicio de las costeras más importantes (besugo y bonito) de una cantidad fija de lo capturado para su elaboración en escabeche, sistema que estaría vigente, al menos, desde el siglo $\mathrm{XVI}^{47}$. Una de las claves para el funcionamiento de este modelo de venta y, en concreto, para que la subasta por adelantado fuera efectiva, era el establecimiento del precio mínimo de venta, que se recogía en los contratos notariales firmados con los rematantes. A partir de las fechas pactadas de duración del contrato, que a grandes rasgos coincidían con las costeras, todo el pescado que en la venta diaria no se colocara por encima de ese precio se entregaba al rematante al valor fijado en el contrato que, habitualmente, solia oscilar entre uno o dos reales por debajo del mínimo establecido ${ }^{48}$. Una vez recibido, no podía venderlo en fresco, sino que debía escabecharlo y, para ello, obtenía del gremio la exclusividad de su fabricación, lo que le aseguraba que, al margen del mismo, nadie pudiera elaborar, ni vender, ni transportar pescado para que fuera escabechado en otro lugar diferente. Las cofradías necesitaban de los remates para poder mantener unos precios de venta aceptables y aprovechar el pescado que no podían vender en fresco, y para atraer a los posibles licitadores, ofrecían esa cláusula de exclusividad.

Pero la intervención gremial en la venta no se limitaba a controlar el acceso a la misma o a centralizar la comercialización de las capturas en la subasta en común. A su alrededor existían también numerosas normas que tenían como propósito establecer las condiciones óptimas para la salida de la pesca hacia los centros de consumo. Como se ha señalado anteriormente, se fijaban horas concretas a las que realizar las subastas para

${ }^{46}$ Constituciones que se forman para la mas ventajosa pesca por las Lanchas de esta Noble y Leal villa de Rentería, 1799, reproducidas en Erkoreka (1991), p. 455.

47 Barkham (2000), pp. 39.40.

48 «La forma, que sabemos todos en este Pueblo se ha observado y observa en la venta diaria de pesca de Besugo fresco para la Arriería y demas que quieran cargar para lo interior de las Provincias, es que el Mayordomo de Mareantes ó su oficial ventador la pone a remate por un precio alto y subido y baxando progresivamente, compran los arrieros diciendo mio, cada arriero ó comprado en aquel precio que le acomoda; Y se sigue de este modo baxando hasta aquel punto ultimo, en que ya no haya quien en venta publica diga mio y no admita mas baxa y sea preciso dar por acabada la venta de fresco a la arrieria, y aplicar las sobras ó restos al rematante Escabechero.» Archivo Municipal de Lekeitio (AML) (Archivo de la Cofradía de Pescadores de Lekeitio) (ACPL), Libro 6, fol. 543. 
regularizar la venta y atraer a los arrieros. Por otro lado, según la época del año se establecía qué tipo de pescado se podía vender, el orden en el que debían subastarse las especies, o la calidad mínima que debía reunir el pescado para ser incluido en el montón. En general, estas preferencias se establecían en función del interés de los compradores. Por lo tanto, muchas de las normas se mantienen o varían dependiendo de los cambios que se pudieran producir en la demanda. Por ejemplo, desde mediados del siglo Xxx, la demanda de merluza fue incrementándose paulatinamente gracias a la posibilidad de acceder a través del ferrocarril a lugares más distantes, y ello hizo que las cofradías fueran adaptando su venta a las condiciones de mercado, adelantando las horas de venta o cambiando el orden de la subasta ${ }^{49}$.

En realidad, se podría decir que en algunos puertos la organización de la venta comenzaba incluso antes de que las lanchas salieran a la mar. La pesca en la costa vasca se estructuraba en torno a la llamada costera, que se correspondía con el período en el que determinadas especies aparecen y desaparecen del área de actuación de los pescadores. En función de las mismas, las cofradías fijaban fechas de inicio y finalización de las temporadas de pesca más importantes. Se ha escrito que esto respondía al interés que mostraban los gremios en evitar «la expoliación de la riqueza piscícola» ${ }^{50}$; sin embargo, un análisis más profundo de estas normas revela intenciones distintas. Es cierto que hay referencias sobre prohibiciones de pescar tal o cual especie durante algunos momentos del año, pero apenas en ninguna de ellas se argumentan sus efectos negativos sobre la reproducción o la pervivencia de algunas especies. En cambio, en la mayor parte de las ocasiones, implícita o explícitamente, da la sensación de que habría otras razones más vinculadas con las características del mercado, con la seguridad, o también con la preeminencia de ciertos elementos del gremio, que con un supuesto interés conservacionista. Aunque se podrían citar

49 En los años sesenta la cofradía de Lekeitio adelantó la hora de la subasta desde las ocho hasta las seis de la tarde para que los compradores tuvieran tiempo de tomar el tren que les llevaba a Bilbao. AML (ACPL), Libro VII, fols. 85 y 87 (29 de abril de 1867-1 de julio de 1867). Sin embargo, con anterioridad, las dificultades para comercialización en fresco de la merluza hacían que su salida fuera secundaria frente al besugo. Por ejemplo, cerca de diez años antes, en un acuerdo lä misma cofradía de Lekeitio señalaba que se subastarán antes «[...] la merluza y demás menudencias antes del besugo, por ser conveniente asi para la cofradía y para que los arrieros carguen después su cuota de besugo». Ibidem, Libro VII, fol. 61 (1 de abril de 1857).

${ }^{50}$ Erkoreka (1991), p. 251. 
muchos ejemplos, este acuerdo de la Cofradía de Elantxobe, con la costera del besugo como protagonista, es una buena muestra de lo apuntado ${ }^{51}$,

«Lo primero, que desde el día de San Andrés Apostol, treinta de Noviembre, hasta el día de Ceniza [...] ninguno de los Maestres de Chalupas pueda ir á otra pesca que el de Besugo, pena de trescientos reales de multa, [...] Lo segundo, que desde el día quince de Noviembre, hasta treinta de él [...] tengan licencia de tirar terzas para la pesca de Besugo, Congrio y Merluza; pero pescando una Chalupa hasta diez docenas de Besugo, no pueda quedar, á la pesca del Congrio, pues haciendo lo contrario no podrá entrar el tal Besugo en este Puerto ni en Jurisdicción alguna de esta Anteiglesia, [...] Y en el caso de que no haviendo pescado una Chalupa hasta diez docenas de Besugo, quedase á la pesca del Congrio, u para la venta del día siguiente, trajese el Besugo, pescado en la víspera, separadamente, se le ha de recibir por el Mayordomo, y vender separadamente; y haciendo mezcla con el Besugo de la vispera, y el del día no se le pueda recibir, ni consentir el que se venda [...] Lo quarto, que verificándose antes del día de Ceniza, el no hacer en la altura Besugo, para la pesca se aian de juntar el Mayordomo, y Maestres de Chalupa, á fin de conferir entre si, lo que sea mas conveniente para la Cofradía y sus individuos; $Y$ sin preceder esta circunstancia, si alguna Chalupa, fuese a pescar fuera del Besugo, incurra en la multa $[. .$.$] . Lo quinto, que en tiempo de quaresma ninguno pueda$ ir á la pesca del Congrio, sin que proceda la Junta del Mayordomo, Maestres de Chalupas, y Señeros, bajo la pena del perdimiento de la pesca [...]».

\section{LA DEFENSA DE LOS DERECHOS}

Hasta ahora hemos descrito como si fuera de una manera estática algunos aspectos de la intervención gremial en la actividad pesquera. A partir de ahora, en cambio, trataremos de acercarnos a las relaciones de las cofradías con otras instituciones o individuos, y a las relaciones entre los propios agremiados, en un tiempo en el que las circunstancias comenzaban a cambiar. Desde mediados del siglo XIX, aproximadamente, la pesca en el País Vasco entró en un proceso lento de apertura, que se aceleraría en las décadas finales de la centuria. Un lento crecimiento de la demanda en los decenios centrales del siglo, gracias al desarrollo de una incipiente industria conservera-escabechera tras el traslado de las aduanas a la costa en $1841^{\mathrm{52}}$, así como una cierta mayor valorización del pescado en los mercados del

51 AFB, Protocolos de Gernika, Caja 117, Manuel Francisco de Foruría (10 de febrero de 1775).

${ }^{52}$ A este respecto, ver López Losa (1997b, 2000). 
interior, fueron atrayendo la atención de particulares hacia el negocio de la pesca. Además, las instituciones liberales veían a las cofradías de pescadores como un remanente del pasado que no se adaptaba a las condiciones jurídico-sociales del nuevo régimen.

Aunque las críticas de los ilustrados en contra de los gremios profesionales fueron frecuentes, no fue hasta 1813 cuando se decretó su disolución en las Cortes de Cádiz, medida que fue confirmada finalmente por Real Orden en 1836. Sin embargo, estas disposiciones no afectaron a los marítimos por una razón exclusivamente jurídica: mientras estuvieran vigentes las Ordenanzas Generales de la Armada de 1748 y la Ordenanza de Matrículas de 1802, las cofradías seguían dependiendo de las autoridades de marina, y no cabía para ellas justicia ordinaria. De todas maneras, como resultado la presión tanto de individuos interesados en abrir el sector a la competencia como de las nuevas autoridades locales o provinciales fueron perdiendo paulatinamente privilegios hasta que por Real Orden de 11 de junio de 1864 se declararon legalmente disueltos todos aquellos que no dispusieran de los pertrechos necesarios para el auxilio de buques y el calamiento de almadrabas ${ }^{53}$. En el País Vasco, en cambio, al seguir vigente la Ordenanza de 1802 y sus disposiciones particulares para la marinería vasca, todas estas medidas no tuvieron efecto.

Sin embargo, ello no impidió que las autoridades civiles trataran de aplicar la normativa general sobre gremios marítimos también en la costa vasca. Se sabe que entre 1842 y 1847 , las autoridades políticas vizcaínas intentaron disolver en varias ocasiones las cofradías en virtud de que eran instituciones que no se adecuaban a las leyes vigentes, ya que limitaban la libertad de industria al impedir la competencia y, a su vez, tampoco permitían a sus miembros pescar libremente. La base jurídica que utilizó, por ejemplo, el Gobierno Político de Vizcaya fue la propia especificidad vasca en cuanto a las reclutas para la Armada que hacía que sus marineros y pescadores dependieran de la jurisdicción ordinaria, lo cual haría posible su intervención para transformar los gremios en sociedades de socorros mutuos acordes con la legalidad ${ }^{54}$. El único recurso que les quedaba a las cofradias vizcaínas era recurrir a las autoridades de marina. Éstas, en contra de lo dispuesto por el Gobierno Civil, afirmaron que si bien las

5) Según el art. $8^{\circ}$ del Real Decreto de 1864: «Los matriculados quedan como todos los españoles en plena libertad para continuar asociados particularmente o para asociarse de nuevo con el fin que tuvieren convenientes, sujetándose a lo que determinen las leyes.» Claver (1989), pp. 457-462.

${ }^{54}$ AMB, Caja 14. Marina 1847-1889. 
Ordenanzas de 1802 señalaban la dependencia de los pescadores vascos de la jurisdicción civil, una Real Orden de 7 de junio de 1806 modificaba esta situación y hacía que todo lo concerniente a la pesca pasara a ser competencia de la marina, con lo que las cofradias quedaban protegidas por el paraguas de las Ordenanzas generales de 1748 y las de Matrículas de 1802 , situación que quedaba reforzada por otras disposiciones de marzo de 1834 y agosto de 1841 que confirmaban que la legislación abolitoria de los gremios no era aplicable a los de marina ${ }^{55}$.

Similares resultados obtuvieron aquellos individuos que pretendían no sólo pescar, sino también vender o escabechar pescado fuera de los cauces de la cofradía. Están documentados diversos intentos de escapar del monopolio gremial que finalmente no prosperaron por distintas razones. Aunque es desde mediados del siglo XIX cuando estas tensiones parecen alcanzar mayor intensidad, en coyunturas en las que la demanda de pescado crecía, como a finales del siglo XVIII, también se pueden encontrar disputas parecidas. Sin pretender un análisis exhaustivo, los siguientes casos constituyen un ejemplo de este tipo de conflictos. En 1770 se instaló en Ajangiz una fábrica de escabeches sin que sus dueños establecieran convenio alguno con las cofradías, lo que levantó las suspicacias de los propios gremios y de los rematantes. Sin embargo, como recoge Erkoreka, los ataques no comenzaron hasta que varios mareantes de Lekeitio llevaron a este establecimiento una partida de besugo. El gremio de la villa les sancionó duramente por incumplir las condiciones establecidas en el remate, y junto a los de Bermeo y Mundaka elevaron una protesta al Señorío que, unos años más tarde, en 1774, acabó confirmando la exclusividad gremial del escabechado ${ }^{56}$. Pocos años antes, en ese mismo contexto, la Real Sociedad Bascongada de Amigos del País intentó impulsar la creación de la llamada Compañia General de Pesca Marítima con el objetivo de fabricar merluza seca y salada en régimen de privilegio para el disfrute de la pesca en los puertos vizcaínos en los que se instalara, intenciones que pronto se extendieron hacia la elaboración de todo tipo de pescado salado, seco, ahumado

"5 «Veredicto de Consejo Superior de la Armada, 14 de junio de 1848», AMDAB, Matrículas, Asuntos Particulares, legajo 2042. AMB, Caja 14. Marina, 1847-1889.

56 Los citados gremios solicitaron la expedición de una Cédula real o Provisión disponiendo que $\ll[. .$.$] ninguna persona de qualquier calidad ó condición que se propase a$ eregir construir ni usar de semejantes fábricas en la cormarca o distancia a lo menos de ocho leguas a cada uno de los puertos». La institución foral, finalmente, dictaminó que «[...] usen de su derecho como corresponde a las cofradías de mareantes de algunos puertos, que pretenden que solamente el rematante de cada uno de ellos pueda hacer escabeche de besugo y atún en el distrito del Señorío». Erkoreka (1991), pp. 288-829, nota 168. 
o escabechado. La reacción contraria de las cofradías del Señorío fue inmediata, puesto que, además, en el proyecto se planteaba la necesidad de fijar un precio para el pescado más o menos estable, algo a lo que los gremios se iban a oponer rotundamente porque significaba intervenir el mercado y terminar con el sistema de venta propio. La fuerte oposición de las cofradías vizcaínas interrumpió el proceso de formación de la empresa que, como alternativa, intentó trasladarse a puertos guipuzcoanos; pero, al igual que en Vizcaya, no tuvo éxito. Como consecuencia de este primer fracaso, la Compañia trató de llegar a un acuerdo con las cofradías, proponiendo hacerse cargo del pescado que sacaban a remate a los precios que hubiesen causado en el último quinquenio, con la condición de que siempre que no hubiera mejor postor, y de que algún rematante igualara su oferta, tuviera preferencia. Sin embargo, exigía, a cambio, total libertad en cuanto a la elaboración de escabeches y salazones, algo a lo que tampoco estaban dispuestas a acceder las agremiaciones. El fracaso de todas sus tentativas trajo su disolución en $1782^{57}$.

En el siguiente caso, en cambio, el protagonista no fue el monopolio de escabeches, sino el de la pesca y la venta del fresco. En los años sesenta y primeros setenta del siglo $\mathrm{XIX}$ se conocen varios casos de pescadores que se quejan a las autoridades civiles por los obstáculos que ponía la cofradía de Bermeo para que pudieran pescar o vender libremente en ese puerto, como así lo permitiría supuestamente el Fuero vizcaíno. Sin embargo, todos estos intentos de actuar fuera de la influencia de la cofradía fracasaron porque ésta consiguió que tanto las autoridades civiles provinciales como las locales, a instancias de las de marina, rechazaran las protestas, con el argumento de que mientras se mantuviera el sistema de reclutamiento sostenido por las Ordenanzas ya citadas, todo aquel que quisiera pescar o navegar debía inscribirse obligatoriamente en una cofradía ${ }^{58}$. Por lo tanto, mientras no se produjera ninguna transformación en las reglas de juego, la cofradía seguía disfrutando de la exclusividad de pesca. No obstante, a partir de los años setenta el entramado institucional que sostenía el monopolio gremial comenzó a desmoronarse.

57 Astigarraga (1993), pp. 152-154.

${ }^{58}$ En AMB, Caja 14, Marina, 1847-1889, un buen número de comunicaciones entre las autoridades civiles de la provincia, el ayuntamiento y los afectados. Una visión algo más amplia en López Losa (2000), pp. 183-188. 


\section{EL CAMBIO INSTTTUCIONAL Y SUS CONSECUENCIAS}

Los problemas que atravesaron las cofradías durante el siglo XIX, en especial en su segunda mitad, no respondían a situaciones aisladas. El desarrollo de la industria transformadora, así como un lento pero paulatino incremento de la demanda de pescado fresco, gracias a la progresiva mejora de los transportes y a la urbanización, fueron dos de los factores que empujaron no sólo un proceso de cambio técnico general, con el empleo de artes y sistemas de pesca cada vez más intensivos, sino también reclamaciones cada vez más frecuentes de liberalización del sector.

Hasta las últimas décadas del siglo difícilmente se podría hablar de una legislación pesquera general en España. En teoría, dentro de las aguas territoriales, la titularidad de los recursos marinos correspondía al Estado $\mathrm{y}$, por lo tanto, también era el encargado de establecer el marco legal que gobernaba su aprovechamiento. Hasta su abolición en 1873, la Matrícula de Mar había sido el medio por el que las autoridades habían regulado la participación de la mano de obra en la pesca, quedando ésta como una actividad privativa de los inscritos en las listas de la Armada. Por otra parte, el Estado también tenía capacidad, en teoría, para decidir cuándo y cómo se podía pescar; es decir, a través de diferentes normas, la administración decidía cuáles eran los sistemas de pesca permitidos y cuáles los prohibidos 59 . Pero tampoco se podría hablar de la existencia de cuerpo legislativo homogéneo. En general, se componía de una multitud de disposiciones particulares, en bastantes ocasiones contradictorias entre sí, que se dictaban, generalmente, como resultado de protestas o peticiones elevadas por grupos de pescadores o armadores de diferentes puntos de la costa española. La normativa desarrollada no respondía a un plan o estudio previo, sino que se iba produciendo, en la mayor parte de los casos, según se presentaban los problemas. De todas maneras, si algo hubiese que destacar, en su conjunto, sería el claro carácter conservacionista que destilaba.

Durante el siglo xvin, la percepción de una naturaleza inmutable e imperecedera fue cediendo paso a una visión más dinámica y finita del

59 Las prohibiciones se aplicaban a todos los pesqueros españoles, tanto dentro como fuera de las aguas territoriales, puesto que la jurisdicción se aplicaba sobre la embarcación y no sólo sobre el espacio. De ahí que el uso de sistemas de pesca como el arrastre a vapor estuvieran en teoría prohibidos para los ciudadanos españoles aunque se emplearan en aguas internacionales sobre las que España no tenía capacidad jurisdiccional alguna. López Losa (1997a), pp. 179-182. 
mundo natural y sus recursos. Por este motivo, eran necesarias leyes y distintas medidas de protección que racionalizaran y regularan su aprovechamiento ${ }^{60}$. Desde el punto de vista de la pesca, las ideas de Sáñez Reguart, plasmadas en diferentes obras, pero fundamentalmente en su Diccionario bistórico de las artes de pesca en España, y en el fallido Proyecto de una Ley general de pesca, constituirían un buen ejemplo de cómo la preocupación por la conservación de los recursos, la regulación de su uso en función del conocimiento existente sobre la biología y el comportamiento de la especies, pero también por cuestiones sociales, influían en una visión que podría considerarse conservadora del mundo pesquero español, y que aparecería presente en la amplia legislación particular desarrollada a partir de la segunda mitad de la centuria.

Saltando en el tiempo, poco más de medio siglo después de que Sáñez publicara su diccionario, en 1865, se creó la Comisión Permanente de Pesca. Esta comisión nació como un organismo consultivo en el que participaban industriales, funcionarios de la marina y naturalistas, y cuya principal función era la de realizar informes sobre el sector que sirvieran a las autoridades como base a la hora de legislar ${ }^{61}$. Sin embargo, en lo básico, los estudios y recomendaciones que emitieron apenas supusieron cambio alguno con respecto a períodos anteriores, por lo menos hasta los años ochenta ${ }^{62}$. Pero detrás de ese supuesto, y probablemente real, interés por la conservación o el aprovechamiento eficiente de los recursos pesqueros, como se ha apuntado, había otro tipo de consideraciones de carácter social. Si la pesca era el vivero que alimentaba de hombres a la Armada, era lógico que el Estado tratara de compensar y atraer a los marineros y pescadores; en cierto modo, la Matrícula no suponía sino un intercambio entre el Estado y éstos. A cambio del servicio, los individuos inscritos dispondrían del monopolio de las actividades marítimas, defendido y refrendado por la ley. Es cierto que la dureza del servicio naval retrajo la entrada de la mano de obra y de la inversión en el sector ${ }^{63}$, pero también es cierto que el Estado siempre trató de defender a los matriculados, y en general, tomó una pos-

${ }^{60}$ Urteaga (1987), pp. 102-103.

${ }^{61}$ Fernández Duro (1868), pp. 10-25.

${ }^{62}$ Fernández Duro (1868, 1869); Salas y García Solá (1876); García Solá (1880), y Gutiérrez Vela (1885).

${ }^{63}$ Carmona (1983), pp. 443-448, y Ocampo (1990), p. 125. Ver también, por ejemplo, Archivo Histórico Nacional, Marina, Navegación marítima, legajo 3208, exp. 374. 
tura defensiva ante cualquier novedad técnica que pudiera amenazar la paz social en las comunidades costeras ${ }^{64}$.

El proceso de cambio institucional se inició, primero, con la desaparición de la Matrícula de Mar en marzo de 1873, lo que liberalizó el acceso de la mano de obra al sector. Se continuó con el desestanco de la sal en 1880 , pero el primer gran avance, en teoría, se daría en 1885 . El primero de enero de ese año, por medio de Real Orden, se promulgó el Reglamento de la libertad de pesca reglamentada. Esta nueva ley significó, por una parte, la nacionalización de los recursos dentro de las aguas territoriales españolas ya que, a partir de entonces, el Estado se convirtió en el encargado exclusivo de producir y hacer cumplir las normas que regulaban la actividad pesquera. Sin embargo, tampoco supuso un cambio radical en las formas de gestión con respecto a tiempos anteriores, puesto que todavía mantenía restricciones al uso de artes intensivas. Por otra parte, los propios miembros de la Comisión reconocían que era muy difícil elaborar reglas generales aplicables para todo el país, desde el momento en el que el litoral español presentaba zonas muy diversas, tanto por la naturaleza de las aguas como por los usos o costumbres imperantes entre los pescadores de las diferentes regiones ${ }^{65}$. A pesar de la variedad de disposiciones que se aplicaban a cada región, e incluso a cada distrito marítimo, lo cierto es que, paulatinamente, la actividad pesquera se fue liberalizando, hasta que acabó declarándose libre la pesca de arrastre a partir de las tres millas de la costa en 1898 y, ya definitivamente, en 1905, cuando por Real Orden de 29 de agosto de 1905 se declaró libre la pesca más allá de las seis millas ${ }^{66}$. A partir de entonces desaparecieron todas las restricciones al uso por cualquier tipo de arte fuera de las aguas jurisdiccionales. De todas maneras, lo cierto es que en la mayor parte de los casos, las leyes iban por detrás y no hacían sino regularizar situaciones, en la mayor parte de los casos, preexistentes ${ }^{67}$.

¿Cómo afectó todo este proceso de cambio institucional a las cofradías de mareantes vascas? Como se había apuntado, hasta entonces habían

${ }^{64}$ Ver, por ejemplo, la polémica desarrollada en torno a la difusión de las parejas de bou en el Levante español en muchas de las Memorias y Anuarios de la Comisión Central de Pesca (nota 62).

${ }^{65}$ García Solá (1888), pp. 135-136.

${ }^{66}$ López y Medina (1906), pp. 77-79.

67 Según Giráldez, la debilidad y la indefinición en casos de la legislación pesquera dejaba la puerta abierta, en sus palabras, al «lasseiz faire, precisamente lo que estaba exigiendo y practicando sin ningun rubor parte del sector». Giráldez (1996), p. 212. Sobre el cambio institucional y el cambio técnico en España, ver Giráldez (1993, 1996, 1997a, 1997b); López Losa (1997a, 1999a, 2000). 
logrado resistir todos los envites gracias a su estrecha vinculación con la recluta de marineros para la Armada. Sin embargo, la Ley de 22 de marzo de 1873 que suprimió la Matrícula de Mar y declaró el libre ejercicio de las industrias marítimas para todos los habitantes de España, incluía un apéndice en el que se declaraba su aplicabilidad en las provincias vascongadas, quedando abolidas todas las prerrogativas contenidas en el artículo 2. ${ }^{\circ}$, Título 11, de las Ordenanzas de Matrículas de 1802 con relación a los servicios marítimos en la Armada. Ello significó la instauración de la libertad general de pesca y, en consecuencia, el fin del monopolio gremial.

No mucho más tarde, en 1878, la cofradía de Bermeo presentó un proyecto de nuevas ordenanzas a las autoridades de marina para sustituir las vigentes originarias del siglo XIV ${ }^{68}$. Aunque el gremio argumentaba que lo que se pretendía con las mismas era cubrir el vacío que en el tema de la seguridad en la pesca dejaban las Ordenanzas anteriores, en realidad lo que buscaban era prohibir de manera legal la salida a la pesca durante una buena parte del año a las embarcaciones que no cumplieran con unas características y medidas determinadas. La ausencia de regulación estricta sobre el tema hacía que fuera frecuente la presencia de las llamadas lanchas menores en las pesquerías de altura, y que según los órganos de dirección de la cofradía se produjeran numerosos naufragios por la menor resistencia de las mismas en comparación con las llamadas lanchas mayores ${ }^{69}$. Estas disputas parece que comenzaron a principios del decenio de los cincuenta, y aunque las autoridades civiles sugirieron, tras consulta de la cofradía, que se elaborara una lista con los requisitos que las lanchas debían cumplir para acudir a las diferentes pesquerías, la ausencia de cualquier referencia en las ordenanzas hacía que muchas de las lanchas menores que habían ido proliferando en el puerto desde los años cuarenta acudieran en número creciente a las costeras de altura. Pero, en realidad, al margen de la seguridad, lo que se escondía detrás del proyecto de renovación de las ordenanzas era el intento de los propietarios de las lanchas mayores, que controlaban los órganos de gobierno del gremio, de conservar el control de la explotación de las especies económicamente más rentables, en particular el besugo, el bonito, y la merluza ${ }^{70}$.

${ }^{68}$ Proyecto de nuevas Ordenanzas para la Cofradía de Bermeo de 1878. AMDAB. Pesca. Asuntos Particulares, legajo 2147. Sobre este tema, ver López Losa (2000), pp. 173-183.

${ }^{69}$ El principal ejemplo que utilizaban para justificar esta propuesta era el de la famosa galerna de abril de 1878 en la que volcaron veintiuna lanchas menores y sólo una mayor. Ibidem.

${ }^{70}$ Un análisis más extenso en López Losa (2000), pp. 172-183. 
Sin embargo, estas nuevas Ordenanzas contenían todavía artículos que contravenían claramente lo dispuesto en la Ley de 1873; es decir, seguían manteniéndose las mismas prohibiciones de pesca y venta a los no miembros de la cofradía, prohibiendo la venta libre de pescado a embarcaciones de otros puertos, obligando a todo quien quisiera pescar a agremiarse y a obedecer las decisiones de los cargos de la cofradía en todo lo concerniente a la actividad extractiva y la comercialización, etcétera ${ }^{71}$. Esto provocó el rechazo del proyecto por parte de las autoridades de marina, ya que, además de invadir atribuciones propias de la Marina como los juicios de faltas o la regulación de la actividad pesquera, iba directamente en contra de la libertad de industria establecida por la citada Ley ${ }^{72}$. Así, a pesar de las numerosas reclamaciones del gremio, las ordenanzas no fueron aprobadas hasta 1886, tras adecuarlas a la legalidad vigente. A pesar de todo, la insistencia de la cofradía bermeana hizo que la administración de marina volviera a estudiar el caso y acabara aceptando en 1888 el establecimiento de unas medidas mínimas para las lanchas que pretendían participar en las pescas de altura, cuestión que más que probablemente estuviera detrás de la división del gremio en dos ese mismo año ${ }^{73}$.

A partir de entonces, las cofradías perdieron toda la capacidad legal para intervenir en la gestión o regulación de la actividad pesquera, puesto que esta responsabilidad pasó a manos de las comandancias de marina y de las juntas de pesca locales y provinciales. Es cierto que las nuevas reglamentaciones apenas se diferenciaban en nada de las prácticas anteriores, y que las cofradías siguieron manteniendo un papel relevante como fuente de información y asesoramiento (función que siguen cumpliendo aún hoy en día); sin embargo, su desarrollo estaba ahora en manos públicas $^{74}$. Ahora bien, la libertad de pesca no trajo la desaparición del modelo productivo gremial, y el funcionamiento económico de muchas comuni-

71 Ibidem. Ver, por ejemplo, arts. 96 y 97. Ibidem: «La que el cabildo de mareantes de Bermeo pretende ejercer sobre sus individuos llega hasta el estremo de privarles del derecho de propiedad sobre los que legitimamente adquieren arrogándose el gremio la facultad de vender la pesca, de fijar su precio y de hacer las rebajas que tenga por conveniente.» Ibidem, Comunicación de la Capitania General de Marina del Departamento del Ferroi al Ministro de Marina, 3 de marzo de 1879 , fol. 7.

72 Por ejemplo, título 2, art. 7; título 4, art. 22; títulos 8, 9, 10; título 15.

${ }_{73} \mathrm{AMDAB}$, Pesca, Asuntos particulares, legajo 2156.

${ }^{74}$ Ejemplos hay muchos. En el caso vasco, por señalar algunos, Reglamento para la pesca con Trainas en los puertos de Lequeitio, Ondärroa, Bermeo y Elanchove, López Medina (1906), pp. 135-136; Reglas para el buen gobierno y policia de la pesca en las aguas de la provincia maritima de Guipuzcoa... aprobadas por Real Orden de 20 de diciembre de 1902, ibidem, pp. 138-140; Reglamento de pesca del distrito de Lequeitio aprobado en 1908, López 
dades pesqueras vascas siguió girando en torno a la cofradía. Su existencia, y la adscripción de los pescadores a la misma se podría decir, entonces, que no era producto sólo de los beneficios económicos que surgirían del disfrute de los citados derechos exclusivos de pesca. Fundamentalmente sería el resultado de la existencia de un comportamiento productivo y social homogéneo, transmitido de generación en generación, que daba sentido y fundamento a la comunidad.

Pero los cambios fueron más amplios de lo que podría parecer porque el lento, pero progresivo, cambio institucional coincidió con otro proceso de innovación, en este caso, técnico. La desaparición de la exclusividad a partir de 1873 y la evolución de la normativa pesquera, en especial a partir de 1885, abrió las puertas a la competencia. El cambio institucional, en este sentido, vino acompañado con el desarrollo en el País Vasco de un nuevo modelo de pesquería completamente diferente a las formas tradicionales, y que iba a tener consecuencias profundas en la estructura productiva gremial: el arrastre a vapor ${ }^{75}$. Pero lo que pasaría por ser el clásico problema causado por la introducción de una tecnología más avanzada y el desplazamiento de unos productores con una menor capacidad productiva, habría que analizarlo en un contexto más amplio. Desde un punto de vista económico, no hay duda de que el arrastre era mucho más productivo que los sistemas tradicionales de anzuelo o red; pero también es cierto que su mayor intensidad de pesca rompió un equilibrio secular entre productores y recursos. Las playas de la estrecha plataforma continental de la parte sudeste del Golfo apenas pudieron sostener durante unas décadas la presión de una pequeña flota arrastrera donostiarra. En realidad, no pasaron muchos años desde que comenzara a pescarse al arrastre para que los caladeros de merluza y otras especies demersales comenzaran a dar los primeros síntomas de sobrepesca, ya a fines del XIX. Aunque las cofradías vascas solicitaron en numerosas ocasiones la prohibición del arrastre, o al menos su alejamiento de las playas en las que actuaban los pescadores artesanales, la imposibilidad del Estado de imponer su jurisdicción en aguas internacionales lo hacía complicado ${ }^{76}$.

Medina (1908), pp. 104-110, o el correspondiente al puerto de Bermeo aprobado en 1909. López Medina (1909), pp. 153-161.

75 Una visión más amplia de los conflictos surgidos en López Losa (1997a, 2000).

${ }^{76} \ll[\ldots]$ que creemos debe prohibirse [el arrastre] en absoluto ó por lo menos limitarse a zonas superiores, y en todo caso que no destruyeran la pesca comprendida en la zona costera hasta donde acuden las lanchas de nuestros puertos, pues se está haciendo de una manera notable la disminución constante [...] debido sin duda alguna al referido sistema 
Pero, en conjunto, la difusión del arrastre acabó provocando la quiebra de una estructura productiva secular al romper el equilibrio en el calendario productivo de las comunidades pesqueras tradicionales. La pérdida de control y la progresiva desaparición de recursos pesqueros tan valiosos como la merluza o el besugo ${ }^{77}$, dejó a los pescadores sin la posibilidad de obtener ingresos durante gran parte del otoño-invierno, tiempo en los que estas dos especies habian venido siendo capturadas desde tiempo inmemorial, con importantes consecuencias económico-sociales en los puertos ${ }^{78}$. Y, sin embargo, las alternativas de sustitución eran bien pocas. Mientras que la pesquería industrial podía hacer frente al problema de la sobrepesca extendiendo su radio de actuación, las limitaciones tecnológicas resultado de la falta de capitalización de la pesquería tradicional lo impedían. Por otra parte, es cierto que durante el primer tercio del siglo $\mathrm{xx}$, y por impulso de una pujante industria transformadora, las capturas de especies susceptibles de ser elaboradas en conserva, escabeche o salazón como el bonito o la anchoa pudieron compensar en parte la pérdida económica, pero no así el desequilibrio en la distribución de los ingresos anuales. Además, se trataba de especies de un valor medio más bajo y unas capturas más variables que la de las anteriores, con lo que la incertidumbre no sólo seguía estando presente durante todo el año, sino que podía acentuarse todavía más.

de pesca por arrastre, que destruye el germen productor de dichas especies hasta el estremo de que sea probable que muy pronto desaparezcan de esta costa, dando lugar a un verdadero conflicto social, si se tiene en cuenta la numerosa población que en la misma vive de la industria pesquera que va quedando reducida a las especies de paso». AFB, Sección Administrativo, carpeta 550, exp. 1 (23 de noviembre de 1901).

${ }_{77}$ Mientras que respecto a la merluza está fuera de toda duda el impacto del arrastre, en el caso del besugo no está tan claro su influencia, ya que, en principio, no era especie objetivo para la flota arrastrera, y sus capturas siempre fueron bastante limitadas. Sin embargo, sí se achacaba a los vapores arrastreros la destrucción del medio en el que el besugo y otras especies realizaban la cría, dificultando cada vez más su reproducción.

78 «[...] los vapores (algunos) de la matrícula de San Sebastián [...] es indudable que son ellos la verdadera causa de que en las meses de invierno sufran los laboriosos y honrados marineros de nuestra costa las torturas que la miseria produce y el hambre ocasiona. Antes de que este sistema de pesca fueron empleados en la costa del Cantábrico, no era sólo el besugo el elemento de riqueza que aportaban los marineros desde las calas hasta los puertos; una infinidad de pescados diferentes traídos en cantidad considerable, servían para alimentar a nuestros pescadores y para producir rendimientos con los cuales podían subvenir á sus más perentorias necesidades» AFB, Sección Administrativo, carpeta 550, exp. 1. Ver Rodríguez Santamaría (1911b), p. 58. Autores como Basterrechea se referían a claros problemas de subsistencia durante el inviemo entre las familias pescadoras vascas en los primeros años veinte. Basterrechea (1928), pp. 117-118. 


\section{EPÍLOGO}

Detrás de toda esta disputa, que causó disturbios, manifestaciones e incluso debates de cariz político, se estaba librando otra batalla en la que se enfrentaban dos maneras diferentes de pescar, de organizar la producción, y de entender el mundo que les rodeaba ${ }^{79}$. Si la manera en la que el individuo percibía su entorno socionatural (que se convierte en ideología para el conjunto de la sociedad, y que acaba transmutándose en leyes que regulan la actividad humana) había justificado durante siglos el funcionamiento gremial, los cambios que se estaban operando desde la segunda mitad del siglo XIX estaban transformando de manera radical la percepción de la naturaleza y de sus posibilidades, y, por lo tanto, la ideología y la ley. La progresiva ruptura de las barreras tecnológicas que habían limitado la explotación de los recursos naturales estaba abriendo la puerta a una visión de una naturaleza plena de recursos inagotables. Esto acabó plasmándose en leyes que facilitaron su uso, en muchas ocasiones, sin apenas regulación. Las consecuencias sociales que podía tener la utilización intensiva de tecnología moderna siempre se justificaban como un daño menor frente a los grandes beneficios que podía generar al conjunto social.

Uno de los grandes conocedores de la pesca española en el primer tercio del siglo $\mathrm{xx}$, Benigno Rodríguez Santamaría, recogió en muchas de sus obras la lucha y las protestas de aquellos que se oponían a la difusión de los nuevos métodos de pesca. Sin embargo, él era un acérrimo defensor del uso de artes intensivas como medio de creación de riqueza. La solución a los problemas que generaba la competencia de la nueva pesquería capitalista pasaba, en su opinión, por la capitalización y la capacitación técnica. Para ello era preciso que se establecieran los medios necesarios (a través de la creación de cooperativas o de pósitos marítimos financiados por el Estado, por citar algunas de sus sugerencias) para que los pescadores tradicionales pudieran acceder a la tecnología y así poder competir en igualdad de condiciones. De ahí que, basándose en sus observaciones y estudios científicos de la época, apenas diera veracidad a las denuncias vertidas contra el arrastre como sistema destructivo, al considerar que el origen de las quejas tenía más que ver con la competencia en los mercados de la pesca que

${ }^{79}$ No es de extrañar que las cofradías recibieran siempre en sus reivindicaciones el apoyo directo de los tradicionalistas y nacionalistas. Ver López Losa (1997a), pp. 206-207. 
con la defensa de una explotación sostenida de los recursos ${ }^{80}$. Al final, no era sino la opinión, influyente, de un representante de esa nueva ideología.

A pesar de todo, las cofradías vascas, a diferencia de lo ocurrido en otros lugares, no sólo no desaparecieron ante la presión de la nueva concepción socioeconómica del mundo que les rodeaba, y de la tecnología que las desplazaba, sino que siguieron funcionando y manteniendo ese carácter de instituciones de supervivencia, y en este caso, también de resistencia frente a la nueva pesquería capitalista ${ }^{81}$. Representaban el rechazo a unas nuevas formas de producción radicalmente distintas a su concepción de la naturaleza y de su aprovechamiento, que se plasmó históricamente en un modelo de organización social concreta. Como señaló la Federación de las cofradías vizcaínas a principios de los años veinte:

«Y no se defiende el arrastre como medio intensivo de producción, pues industria que destruye el elemento natural, industria que paraliza el trabajo, ni es económicamente productora ni es socialmente beneficiosa» ${ }^{82}$.

\section{BIBLIOGRAFÍA}

AgULERA KLINK, Federico (1991): «¿La tragedia de la propiedad común o la tragedia de la malinterpretación de la economía», Agricultura y Sociedad, núm. 61 (octubre-diciembre), pp. 157-181.

- (coord.) (1992): Economía del Agua, Madrid, Ministerio de Agricultura, Pesca y Alimentación, Secretaría General Técnica.

ALSTON, Lee J. (1996): «Empirical work in institutional economics: an overview», en Lee J. Alston, Thráinn Eggertson y Douglass NORTH (eds.) (1996), pp. 25-30.

${ }^{80}$ En realidad, no negaba el hecho de que con las artes de arrastre se capturaran cantidades importantes de crías; sin embargo, también señalaba que éste no era un hecho exclusivo de estas artes, ya que él mismo había sido testigo en muchos puertos del norte de cómo artes de cerco capturaban toneladas de pescado pequeño que era arrojado al mar por no tener salida en el mercado. Ver, por ejemplo, Rodríguez Santamaría (1911a, 1911b, $1915 a, 1915 b, 1915 c, 1916$ y 1920 ).

${ }^{81}$ A diferencia de lo ocurrido en otros casos, apenas hubo trasvase de mano de obra del sector tradicional al moderno industrializado. Los intentos de los armadores de los arrastreros para atraer patrones y pescadores procedentes de la pesca artesanal fueron mayoritariamente infructuosos. La mayor parte de las tripulaciones de los pesqueros de arrastre de la flota guipuzcoana acabaron siendo formadas por inmigrantes gallegos, fundamentalmente, junto con algunos guipuzcoanos del interior. Rodríguez Santamaría (1911b), p. 64; Ossa Echaburu (1989), p. 128.

${ }^{82}$ Carta de la Federación de las Cofradias de Pescadores de Vizcaya a la Junta de Industria Pesquera de la Excma. Dip. Provincial de Vizcaya (17/10/1921). AFB, Sección Administrativo, carpeta 550, exp. 1. 
Alston, Lee J.; EggerTson, Thráinn, y NorTh, Douglass (eds.) (1996): Empirical Studies in Institutional Change, Cambridge University Press.

ANDERsson, Bertil (1999): Swedish and International Fisheries, Rapport från ekonomisk-historiska instituitionen vid Göteborg Universitet, Göteborg, pp. 61-90.

ARrizabalaga, Florentino, y AguirRe, María Ángeles (1986-87): «Aproximación al sector pesquero vizcaíno en el siglo XIX. Producción y comercialización», Bermeo Aldizkaria, núm. 6, pp. 219-330.

Asamblea de Pesca Marítima Vasca. San Sebastián 1925 (1928): San Sebastián, Eusko Ikaskuntza-Sociedad de Estudios Vascos.

Astigarraga, Jesús (1993): «La Compañía General de Pesca Marítima en las costas del mar Cantábrico (1770-1782)», Boletín de la Real Sociedad Bascongada de Amigos del País, XLVIII, 1-2, pp. 133-158.

BARKHAM, Michael (2000): «La industria pesquera vasca peninsular al principio de la Edad Moderna. ¿Una edad de oro?», Itsas, Memoria, núm. 3, pp. 29-75.

Basterrechea, Francisco de (1927): «El problema del arrastre. Soluciones posibles», Asamblea de Pesca Maritima Vasca. Recopilación de trabajos (1928), pp. 117-142.

Berkes, Fikret (ed.) (1989): Common Property Resources. Ecology and Community-Based Sustainable Development, London, Belhaven Press.

BerkEs, Fikret, y FARVAR, M. Taghi (1989): «Introduction and overview», Fikret BERKES (ed.) (1989), pp. 1-17.

BIKANDI, Juan J. (1989): «Cofradías de Pescadores», en VVAA (1989), vol. VI, pp. 19-39.

Blasco Martín, Ana (1998): Mundaka y Sukarrieta, Bilbao, Bizkaiko Foru Aldundia/Diputación Foral de Bizkaia.

Breton, Yvan; SAVARD, Catherine (1999): «Antropología marítima y economía institucional: El mercado de gambas en Madagascar», en García Allut y PASCUAL. FERNÁNDEZ (coords.) (1999), pp. 11-23.

BROMLEY, Daniel W. (1985): «Resources and economic development: an institutionalist perspective», Journal of Economic Issues, núm. 19 (3), pp. 779-796.

- (1991): «Testing for Commons versus Private Property: Comment», Journal of Environmental Eccnomics and Management, pp. 92-96.

- (1992): «The Commons, Common Property, and Environmental Policy», Environmental and Resource Economics, núm. 2, pp. 1-17.

Caballero, Gonzalo (2001): «La Nueva Economía Institucional», Sistema, núm. 161, pp. 86.

Carmona Badía, Joám (1983): Producción rural e actividades marítimo pesqueiras na Galiza, 1750-1905, Santiago de Compostela, tesis doctoral inédita.

Ciriacy-Wantrup, S. V., y Bishop, R. C. (1992): «La propiedad común como concepto en la política de los recursos naturales», en AGUILERA KLINK (1992), pp. 339-358.

Ciriquiaín-GaizTarro, M. (1961): Los vascos en la.pesca de la ballena, San Sebastián, Biblioteca Vascongada de Amigos del País.

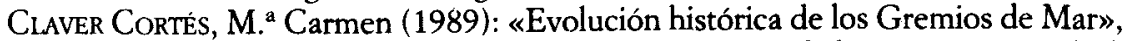
en Jomadas sobre economia y sociologia de las comunidades pesqueras, Madrid, Ministerio de Agricultura, Pesca y Alimentación. Secretaría General Técnica, pp. 453-462. 
Delgado Cendagortagalarza, Ander (1998): Bermeo en el siglo XIX. Política y conflicto en un municipio pesquero vizcaino (1912-1955), Donostia, Eusko Ikaskuntza.

Demsetz, Harold (1967): «Toward a Theory of Property Rights», American Economic Review, núm. 57, mayo, 2, pp. 347-359.

Drobrak, John N., y NyE, John V. C. (eds.) (1997): The frontiers of the New Institutional Economics, Academic Press.

EGAÑA, Bernabé Antonio de (1992): Instituciones y colecciones histórico-legales pertenecientes al gobierno municipal, fueros, privilegios $y$ exenciones de la $M . N$. y M. L. Provincia de Guipúzcoa, edición preparada por Luis Miguel Díaz de Salazar y M.a Rosa Ayerbe Iribar, Donostia-San Sebastián, Gipuzkoako Foru Aldundia/Diputación Foral de Gipúzkoa.

EgGERTSSON, Thráinn (1992): «Analyzing Institutional Successes and Failures; A Millennium of Common Mountain Pastures in Iceland», International Review of Law and Economics, núm. 12, pp. 423-437.

- (1995): El comportamiento económico y las instituciones, Madrid, Alianza Editorial.

- (1996): «A note on economic of institutions», Lee J. ALSTON, Thráinn EGGERTSSON y Douglass NORTH (eds.) (1996), pp. 6-24.

- (1998): «Sources of Risk, Institutions for Survival and Game against Nature in Premodern Iceland», Explorations in Economic History, núm. 35, pp. 1.30.

Engerman, Stanley L. (1997): «Cultural Values, Ideological Beliefs, Changing Labour Institutions», John N. DROBRAK y John V. C. NYE (eds.) (1997), pp. 95-119.

ERKOREKA, Josu I. (1991): Análisis histórico-institucional de las cofradias de mareantes del País Vasco, Vitoria-Gasteiz, Gobierno Vasco/Eusko Jaurlaritza.

Feeny, D.; Berkes, F.; McCay, B., y Acheson, J. (1990): «The Tragedy of the Commons: Twenty-Two Years Later», Human Ecology, vol. 18, 1, pp. 1-17.

Feeny, D.; Hanna, S., y McEvoy, A. (1996): "Questioning the Assumpsions of the "Tragedy of the Commons" Model of Fisheries», Land Economics, 72 (2), pp. 187-205.

Fernández Duro, Cesáreo (1868): Anuario de la Comisión permanente de la pesca para 1868, Madrid, Estrada Díaz y López.

- (1869): Anuario de la Comisión permanente de la pesca para 1869, Madrid.

- (1881): Arca de Noé. Libro sexto de las disquisiciones náuticas, Madrid, Imprenta, Esterotipia y Galvanoplastia de Aribau y C. a (Sucesores de Rivadeneyra).

FERnández Mokeno, José Ramón (1998): «El régimen comunal y la reproducción de la comunidad campesina en las sierras de La Rioja, siglos XVH-XDX», Historia Agraria, núm. 15, pp. 75-111.

FURUBOTN, Eirik G., y RICHTER, Rudolf (1997): Institutions and Economic Theory. The Contribution of the New Institutional Economics, The University of Michigan Press.

García Allut y Pascual Fernández; J. (coords.) (1999): Antropología de la pesca. Actas del VIII Congreso de Antropología, Simposio III, Santiago de Compostela, Federacion de Asociaciones de Antropología del Estade Español/Asociación Galega de Antropología. 
García de Cortázar y Ruiz de Aguirre, José Ángel (1966): Vizcaya en el siglo XV. Aspectos económicos y sociales, Bilbao, Caja de Ahorros Vizcaína.

- (1969): El dominio del monasterio de San Millán de la Cogolla (siglos X a XIII). Introducción a la bistoria rural de Castilla altomedieval, Salamanca, Universidad de Salamanca.

GaRcía SOLÁ, Francisco (1880): Memoria sobre la industria y legislación de pesca que comprende desde el año 1874 al 1879, Madrid, Tipografía de G. Estrada.

GibBS, C. J. N., y Bromley, D. W. (1989): «Institutional Arrangements for Management of Rural Resources: Common-Property Regimes», BERkEs (ed.) (1989), pp. 22-32.

GiRÁLdEz RIvero, Jesús (1993): «El conflicto por los nuevos artes: conservacionismo o conservadurismo en la pesca gallega de comienzos del siglo XX», en Manuel González de Molina y Juan Martínez Alier (eds.) (1993), pp. 233-251.

- (1996): Crecimiento y transformación del sector pesquero gallego (1880-1936), Madrid, Ministerio de Agricultura, Pesca y Alimentación.

- (1997a): «Las bases históricas de la actividad pesquera en España», Papeles de Economia Española, núm. 71, pp. 33-59.

- (1997b): De las Rias a Terranova: La expansión de la pesca gallega (1880-1950), Vigo, Industrias Pesqueras.

González de Molina, Manuel, y González Alcantud, José Manuel (1992): «La pervivencia de los bienes comunales: representación mental y realidad social. Algunas aportaciones al debate sobre "la tragedia de los comunales"», en Manuel González de Molina y José Manuel Gonzalezz Alcantud (eds.) (1992), pp. 251-291.

- (eds.) (1992): La Tierra. Mitos, ritos y realidades, Barcelona.

González de Molina, Manuel, y Martínez Alier, J. (eds.) (1993): Historia y Ecologia, Madrid, Ayer, 11.

Gordon, H. Scott (1954): «The Economic Theory of a Common-Property Resource: The Fishery», Journal of Political Economy, núm. 62, pp. 124-142.

GREIF, Avner (1997a): «Microtheory and recent developments in the study of economic institutions through economic history», David M. KREPS y Kenneth F. WALLIS (eds.) (1997), pp. 79-113.

- (1997b): «On the Interrelations and Economic and Economic Implications of Economic, Social, Polítical and Normative Factors: Reflections from Two Late Medieval Societies», John N. Drobrak y John V. C. NyE (eds.) (1997), pp. 57-94.

- (2000): «The fundamental problem of exchange: A research agenda in Historical Institutional Analysis», European Review of Economic History, núm. 4, pp. 251-284.

Gustafsson, B. (1998): «Some Theoretical Problems of Institutional Economic History», Scandinavian Economic History Review, 46 (2), pp. 5-31.

GutiÉRREZ Vela, Rafael (1885): Memoria sobre la industria y legislación de pesca que comprende desde el año 1879 al 1884, Madrid, Imprenta de la Viuda e Hija de Fuentenebro.

Hannesson, Rögnvaldur (1993): Bioeconomic Analysis of Fisheries, Oxford, FAO/Fishing New Books. 
Hardin, Garret (1968): «The Tragedy of Commons», Science, núm. 162, pp. 1243-1248.

Holm, Poul, y Starkey, David J. (eds.) (1999): Technological Change in the North Atlantic Fisheries, Esbjerg, pp. 225-246.

IRIARTE GoÑI, Iñaki (1997): Bienes comunales y capitalismo agrario en Navarra, Madrid, Ministerio de Agricultura, Pesca y Alimentación.

- (1998): «La pervivencia de bienes comunales y la teoría de los derechos de propiedad: unas reflexiones desde el caso navarro», Historia Agraria, núm. 15, pp. 113-142.

KrePS, David M., y Wallis, Kenneth F. (eds.) (1997): Advances in economics and econometrics: Theory and applications. Seven World Congress Volume II, Cambridge University Press.

LIBECAP, Gary (1989): Contracting for Property Rights, Cambridge University Press. López García, Santiago, y Valdalıso, Jesús María (eds.) (1997): Tecnología, empresa y cambio económico en la España contemporánea, Madrid, Alianza Editorial.

LÓPEZ LOSA, Ernesto (1997a): «Recursos naturales, derechos de propiedad y cambio técnico. La difusión del arrastre a vapor en las pesquerías vascas, 1871-1936», en Santiago López y Jesús María Valdaliso (eds.), pp. 157-209.

- (1997b): «Escabeche, salazón y conserva. Una primera aproximación a la transformación del pescado en el País Vasco (1795-1975)», en VVAA (1997), pp. 80-131.

- (1999): «Institutions, Technical Change and the Development of the Spanish Fishing Industry (1858-1936)», ANDERSSON (ed.) (1999), pp. 61-90.

- (2000): El sector pesquero y la industria transformadora de pescado en el País Vasco. Una historia económica, Tesis doctoral inédita.

- (2002): «Una aproximación al sector pesquero tradicional vasco, 1800-1880», Historia Agraria, núm. 28, en prensa.

LÓPEZ Y MEDINA, Francisco (1906): Colección de tratados internacionales, ordenanzas y reglamentos de pesca, Madrid, Impresiones de Balbino Cerrada.

- (1908): Segundo apéndice a la Colección de tratados internacionales, ordenanzas y reglamentos de pesca, Madrid, Centro Gráfico-Artístico, Imprenta de Moliner y Cís.

- (1909): Tercer apéndice a la Colección de tratados internacionales, ordenanzas y reglamentos de pesca, Madrid, Centro Gráfico-Artístico - Imprenta.

Marz Alkorta, José Agustín (1993): El sector pesquero vizcaíno 1800-1960. Análisis de la interacción de los elementos ambiental, extractivo y comercial en la pesquería, Vitoria-Gasteiz, Departamento de Agricultura y Pesca, Gobierno Vasco, Colección Tesis Doctorales, núm. 19.

McCaY, Bonnie, y ACHESON, James M. (1990): The Question of Commons. The Culture and Ecology of Communal Resources, Tucson, University of Arizona Press.

McEvoY, Arthur F. (1988): «Toward an Interactive Theory of Nature and Culture: Ecology, Production, and Cognition in the California Fishing Industry», WorsTER (ed.) (1988), pp. 211-229.

- (1990): The Fisherman's Problem. Ecology and Law in the California Fisheries, 1850-1980, Cambridge University Press. 
- (1993): «Historia y ecología de las pesquerías del nordeste del océano Pacífico», Gonzalez de Molina y Martínez Alier (eds.) (1993), pp. 189-205.

Moreda Oroza, Guillermo (1966): «Las Cofradías de pescadores en España», Revista Internacional de Trabajo, núm. 2, pp. 536-549.

Moreno FernándeZ, José Ramón (1998): «El régimen comunal y la reproducción de la comunidad campesina en las sierras de La Rioja, siglos XVII y XIX», Historia Agraria, núm. 15, pp. 75-111.

Nieto, Alejandro (1964): Los bienes comunales, Madrid, Revista de Derecho Privado.

NORTH, Douglass (1990): Institutions, Institutional Change and Economic Performance, Cambridge University Press.

NorTh, Douglass C., y Thomas, Robert Paul (1977): «The First Economic Revolution», Economic History Review, 30, núm. 2, pp. 229-241.

- (1973): The Rise of the Western World: A New Economic History, Cambridge, Cambridge University Press.

OCAMPO SuÁrez-VAldés, Joaquín (1993): «Pesca y actividades de transformación en Asturias, 1750-1990: líneas de investigación y primeros resultados», comunicación presentada al IV Congreso de Historia Económica, San Sebastián.

Ossa Echaburu, R. (1989): «El puerto de Pasajes», en VVAA, t. VII.

Ostrom, Elinor (1990): Governing the Commons The Evolution of Institutions for Collective Action, Cambridge University Press.

Rodríguez Santamarí, Benigno (1911a): Diccionario, ilustrado, descriptivo, valorado, numérico de las artes, aparejos e instrumentos que se emplean para la pesca maritima en las costas del Norte y noroeste de España, Madrid.

- (1911b): «Pesca de Altura por arrastres en el Norte y Noroeste de España», Anuario estadístico de la Marina Mercante y de la Pesca. Año 1910, pp. 51-112.

- (1915a): «Artes de Pesca. Pareja», Euskal-Erria, 2. ${ }^{\circ}$ semestre, t. 73, pp. 40-43.

- (1915b): «Otra vez los arrastres», Euskal-Erria, ${ }^{\circ}{ }^{\circ}$ semestre, t. 73, pp. 290-296.

- (1915c): «Artes de Pesca. Bou», Boletín de la Sociedad Oceanográfica de Guipúzcoa, t. IV, núm. 14, pp. 40-46.

- (1916): Los pescadores del Norte y Noroeste de España. Su vida social y particular por provincias, Madrid, Imprenta Alemana.

- (1920): «Pesca con artes de arrastre», Boletin de la Sociedad Oceanográfica de Guipúzcoa, núm. 37, octubre-diciembre, pp. 1-22.

Salas, Francisco Javier de (1879): Historia de la Matrícula de Mar y examen de varios sistemas de reclutamiento maritimo, Madrid, Imprenta de Fontanet.

SAlas, Javier de, y García Solá, Francisco (1876): Memoria sobre la industria y legislación de pesca que comprende desde el año 1870 al 1874, Madrid, Imprenta de T. Fontanet.

SáNez Reguart, Antonio (1791-1795) [1988]: Diccionario bistórico de las artes de pesca nacional (introducción Juan Carlos Arbex), Madrid, Ministerio de Agricultura, Pesca y Alimentación, Secretaría General de Pesca Marítima, facsímil.

Schlager, E.; Blomquist, W., y Tang, S. Y. (1994): «Mobile Flows, Storage, and Self-Organized Institutions for Governing Common-Pool Resources», Land Economics, agosto, núm. 70 (3), pp. 294-317.

Schlager, E., y Ostrom, E. (1992): «Property Rights Regimes and Natural Resources: A Conceptual Analysis», Land Economics, agosto, núm. 68 (3), pp. 249-262. 
Swaney, James A. (1990): «Common Property, Reciprocity and Community», Journal of Economic Issues, vol. XXIV, núm. 2, junio, pp. 451-462.

Tena Garcia, M. ${ }^{a}$ Soledad (1995): «Cofradías de pescadores y concejos en la Marina de Castilla: el caso de la villa de Deba a mediados del siglo XV», en CASTLLL (coord.) (1995), pp. 143-147.

Tовоso, Fernando (1997): «¿En qué se diferencian los enfoques de análisis de la vieja y la nueva economía institucional?», Hacienda Pública Española, núm. 143, pp. 175-192.

UGARTETXEA (UGARTECHEA), José María de (1991a): Lan guztiak, Lekeitioko Udala (Ayuntamiento de Lekeitio). También hay traducción al castellano.

- (1991b): «Arrantza tradizionala Lekeition», en UGARTETXEA (UGARTECHEA) (1991a), pp. 119-256, reproducido de UGARTECHEA, José María de (1967-1968), «La pesca tradicional en Lequeitio», Anuario de Eusko Folklore, t. XII, pp. 9-155.

URTEAGA, Luis (1987): La tierra esquilmada. Las ideas sobre la conservación de la naturaleza en la cultura española del siglo XVIII, Madrid, Serbal/CSIC.

VAA (1989): Itsasoa. El mar de Euskalerria. La naturaleza, el bombre y su bistoria, San Sebastián, Etor, VII tomos.

- (1997): Arrain kontserbak Euskal Herrian. Industria eta ondarea. Las conservas de pescado en el País Vasco. Industria y patrimonio, Donostia/San Sebastián, Untzi Museoa/Museo Naval.

WORSTER, Donald (ed.) (1988): The Ends of the Earth. Perspectives on Modern Environmental History, Cambridge University Press.

Zabala eta Otzamiz-Tremoya, A. (1931): Historia de Bermeo, Guernica, Víctor de Gaubeca.

Zabala URIARTE, Aingeru (1981): «La evolución de la marinería en el norte durante el siglo xvmI», Bermeo, núm. 1, pp. 203-218. 